\title{
The cyclin E regulator cullin 3 prevents mouse hepatic progenitor cells from becoming tumor-initiating cells
}

\author{
Uta Kossatz, ${ }^{1}$ Kai Breuhahn,, ${ }^{2}$ Benita Wolf, ${ }^{3}$ Matthias Hardtke-Wolenski, ${ }^{3}$ Ludwig Wilkens,, \\ Doris Steinemann, ${ }^{5}$ Stephan Singer, ${ }^{2}$ Felicitas Brass, ${ }^{3}$ Stefan Kubicka, ${ }^{3}$ Brigitte Schlegelberger, ${ }^{5}$ \\ Peter Schirmacher, ${ }^{2}$ Michael P. Manns, ${ }^{3}$ Jeffrey D. Singer, ${ }^{6}$ and Nisar P. Malek ${ }^{1,3}$ \\ ${ }^{1}$ Institute for Molecular Biology, Hannover Medical School, Hannover, Germany. ${ }^{2}$ Institute of Pathology, University Hospital Heidelberg, Heidelberg, Germany. \\ ${ }^{3}$ Department of Gastroenterology, Hepatology and Endocrinology, Hannover Medical School, Hannover, Germany. ${ }^{4}$ Institute of Pathology, \\ Nordstadt Krankenhaus, Hannover, Germany. ${ }^{5}$ Institute for Cellular and Molecular Pathology, Hannover Medical School, Hannover, Germany. \\ ${ }^{6}$ Department of Biology, Portland State University, Portland, Oregon, USA.
}

Cyclin $\mathrm{E}$ is often overexpressed in cancer tissue, leading to genetic instability and aneuploidy. Cullin 3 (Cul3) is a component of the BTB-Cul3-Rbx1 (BCR) ubiquitin ligase that is involved in the turnover of cyclin $\mathrm{E}$. Here we show that liver-specific ablation of $\mathrm{Cul} 3$ in mice results in the persistence and massive expansion of hepatic progenitor cells. Upon induction of differentiation, Cul3-deficient progenitor cells underwent substantial DNA damage in vivo and in vitro, thereby triggering the activation of a cellular senescence response that selectively blocked the expansion of the differentiated offspring. Positive selection of undifferentiated progenitor cells required the expression of the tumor suppressor protein p53. Simultaneous loss of Cul3 and p53 in hepatic progenitors turned these cells into highly malignant tumor-initiating cells that formed largely undifferentiated tumors in nude mice. In addition, loss of Cul3 and p53 led to the formation of primary hepatocellular carcinomas. Importantly, loss of Cul3 expression was also detected in a large series of human liver cancers and correlated directly with tumor de-differentiation. The expression of Cul3 during hepatic differentiation therefore safeguards against the formation of progenitor cells that carry a great potential for transformation into tumor-initiating cells.

\section{Introduction}

A genetic alteration frequently observed in cancer tissue is the increased expression of cyclin E (1). For example, the majority of liver cancers express this protein at levels higher than in the surrounding normal tissue (2). Intriguingly, cyclin $\mathrm{E}$ is also able to induce DNA double-strand breaks, which may lead to genetic instability and aneuploid cells (3). Consistent with the importance of cyclin $\mathrm{E}$ in regulating cell proliferation and genetic stability, its expression levels are tightly controlled. In addition to transcriptional mechanisms, cyclin E levels are also regulated by posttranslational modifications that trigger the proteolytic degradation of cyclin E by cullin 1- or cullin 3-dependent (Cul1or Cul3-dependent) ubiquitin ligases. Degradation of cyclin E by the Cul1-dependent ubiquitin ligase requires its interaction with the F-box protein Fbw7, which upon phosphorylation of cyclin E at T380 by GSK3 and T384 by cdk 2 tightly binds to the protein and mediates its polyubiquitination and subsequent proteasomal turnover $(4,5)$. Mutations in Fbw7 have been shown to induce genetic instability, and certain types of human cancers such as $\mathrm{T}$ cell leukemias and cholangiocellular carcinomas frequently show alterations in this gene (6).

Loss of Fbw7 also affects stem cell proliferation by depleting hematopoietic stem cells due to active cell cycling and an increase in the rate of apoptotic cell death (7-9). Conversely, expression of a stabilized version of cyclin $\mathrm{E}$ that can no longer be degraded by the Fbw7-dependent E3 ubiquitin ligase results in an expansion of the

Conflict of interest: The authors have declared that no conflict of interest exists. Citation for this article: J Clin Invest. 2010;120(11):3820-3833. doi:10.1172/JCI41959. pool of proliferating erythroid progenitors with a reduced ability to differentiate and an increase in the rate of apoptosis (10). These results point to a tissue-specific function of cyclin $\mathrm{E}$ turnover in the maintenance of stem cell homeostasis.

In addition to the Cul1-dependent degradation system, a second ubiquitylation complex that employs Cul3 is required for the turnover of cyclin E (11). Cul3 forms a complex called the BTB-Cul3-Rbx1 (BCR) ubiquitin ligase, which controls the degradation of several proteins, including cyclin $\mathrm{E}$, the meiotic spindle formation factor Mei-1, the transcription factor Nrf2, the $\mathrm{Ci} / \mathrm{Gli}$ transcription factor, and the dishevelled protein in the Wnt/ $\beta$-catenin pathway (12-15). Loss of Cul3 in the mouse leads to early embryonic lethality, with some cell types showing increased levels of cyclin E (11). Ablation of Cul3 expression in adult mouse hepatocytes in vivo results in a strong increase in cell size and genetic instability in the Cul3-deficient liver cells (16). While these results point to a central role of the BCR complex in maintaining cyclin E levels and cellular homeostasis, nothing is known about the role of Cul3 in stem cells. We therefore ablated the Cul3 gene using an $\alpha$-fetoprotein-Cre transgene that induces Cre recombinase expression in the developing liver starting at day 9.5 post coitum (p.c.).

In this work, we describe the phenotype of mice in which the $\mathrm{Cul} 3$ gene was selectively deleted in liver tissue. We find that loss of Cul3 leads to a massive expansion of liver progenitor cells that undergo senescence upon induction of differentiation. This process depends on the expression of cyclin $\mathrm{E}$, which in differentiating cells induces DNA damage and subsequent activation of a p53dependent damage checkpoint. Simultaneous loss of p53 results 
in the formation of highly aggressive tumor-initiating cells, which form hepatocellular carcinomas in situ and after transplantation. Differentiation-induced senescence therefore constitutes a new tumor suppressor mechanism in liver cells.

\section{Results}

Loss of Cul3 results in the accumulation of hepatic progenitor cells. To analyze the function of the Cul3-based E3 ubiquitin ligase in liver embryogenesis, we crossed $\mathrm{Cul} 3^{\operatorname{lox} \mathrm{P} / \text { loxp }}$ mice with a transgenic mouse line that expresses the Cre recombinase under the control of albumin regulatory elements and $\alpha$-fetoprotein enhancers (AlfpCre) (17), which directs Cre recombinase expression to the liver starting at day 9.5 p.c. Mice were born at normal Mendelian ratios but only survived until approximately 11 weeks after birth. Most Cul3 $3^{\text {loxP/loxP }}$ AlfpCre mice were significantly smaller than their wild-type littermates, and all of them showed an up to $30 \%$ decrease in body weight at the time of death (data not shown). Upon macroscopic examination, we found that the livers of $\mathrm{Cul} 3^{\operatorname{lox} P / \operatorname{lox} P}$ AlfpCre mice were larger and appeared pale and of firm consistency (Figure 1A) compared with wild-type control organs. Microscopic analysis of the liver tissue and pathological findings revealed an almost complete loss of the normal liver architecture, with a decrease in liver parenchyma and areas of dysmorphic-appearing hepatocytes. These were surrounded by small mononucleated cells of oval or round shape (Figure 1A), which formed strand-like areas of cells that traversed the liver tissue. In addition, we detected a strong increase in connective tissue (Supplemental Figure 1A; supplemental material available online with this article; doi:10.1172/JCI41959DS1), which contributed to the increase in consistency of the Cul3 $3^{\text {loxP/loxP }}$ AlfpCre livers. None of these changes were observed in wild-type liver tissue. To differentiate Cul3-knockout cells from infiltrating stromal cells, lymphocytes, and macrophages, which were all identified on histological examination of the liver tissue, we generated triple transgenic mice by crossing Cul3 $3^{\text {loxP/loxP }}$ AlfpCre mice to $\beta$-galactosidase reporter mice (Rosa26-LacZ). Given that Cre recombinase expression is under the control of albumin regulatory elements and $\alpha$-fetoprotein enhancers, LacZ expression should only be detectable in cells of hepatic origin. As shown in Figure 1B, $\beta$-galactosidase activity was detectable in the small mononucleated cells and in the remaining hepatocytes, indicating that Cre-mediated activation of LacZ expression was successful in these cells in vivo. To further confirm that the activation of the Cre recombinase led to the loss of Cul3, we performed Cul3 Western blot and immunofluorescence analyses of Cul3 expression in primary liver tissues. While whole liver lysates showed a loss of Cul3 at 4 weeks after birth, we could detect a small increase in protein levels from 4 to 8 weeks (Supplemental Figure 1C). We therefore performed immunofluorescence stainings for the Cul3 protein and found that $\mathrm{Cul} 3$ expression was undetectable in hepatocytes and in the mononucleated cells (Supplemental Figure 1D). The increase in $\mathrm{Cul} 3$ protein at 8 weeks was therefore caused by an increase in stromal cells, as shown in Supplemental Figure 1A. In addition, we used albumin staining to analyze whether albumin is also expressed in these small mononucleated cells. Using spleen as a negative control (Supplemental Figure 1B), we show that the AlfpCre transgene is only active in the small mononucleated cells and in hepatocytes, indicating that the cells in which Cul3 had been deleted were of hepatic origin (Figure 1A).

Our histological examination suggested that the population of small albumin-expressing cells in the Cul3-knockout livers might constitute undifferentiated hepatic progenitor cells that had expanded in number upon loss of Cul3. To determine the identity of these cells, we used a panel of antibodies directed against surface epitopes frequently found on liver progenitor cells $(18,19)$. We found that the small mononucleated cells in the Cul3-knockout livers were to varying degrees positive for CK14, CD133, or CD34 expression (Figure 1C), pointing to an increase in the number of progenitor cells in Cul3-knockout livers as compared with wild-type organs. These stainings were confirmed by Western blot analysis of whole liver lysates in which the same stem cell markers could also be detected (Supplemental Figure 2A).

Activation of the liver stem cell pool is frequently found under conditions in which liver cell proliferation is blocked (20). Under such conditions, a population of bipotential liver progenitor cells called oval cells expands and differentiates into mature hepatocytes to restore liver function (21). However, when we compared tissue sections from 4- and 8-week-old livers, we detected a reduction in the number of hepatocytes (Figure 1D) in the Cul3-knockout mice. We used $\beta$-catenin to stain the plasma membrane of these cells, which showed features typical of hepatocytes, thereby allowing us to distinguish them from the small mononucleated cells (Supplemental Figure 1E). In contrast to the hepatocytes, the number of cells expressing the stem cell markers CD34 and CD133 increased over time (Figure 1E), while the CK14-positive cells did not. Our analysis therefore shows that loss of Cul3 in liver tissue results in a massive expansion of the pool of liver progenitor cells that fail to adequately differentiate into mature hepatocytes.

Loss of Cul 3 causes DNA damage in differentiated liver cells but not in hepatic precursors. Next we analyzed why loss of Cul3 results in a block of cellular differentiation. Cul3 had previously been shown to regulate the stability of cyclin $\mathrm{E}$ (11). We therefore measured the expression level of cyclin $\mathrm{E}$ and found it to be strongly increased in $\mathrm{Cul} 3^{\text {loxP/loxP }}$ AlfpCre as compared with Cul3 $3^{\text {loxP/loxP }}$ liver cells (Figure 2A). In addition to cyclin E, we found the levels of Aurora B kinase, another known Cul3 substrate (22), and of the cyclin kinase inhibitor p21 to be increased in these livers. Importantly, cyclin E levels in Cul3-deficient livers were much higher than what we observed under conditions of liver regeneration, in which up to $90 \%$ of all hepatocytes synchronously entered the cell cycle, indicating that the increased expression of cyclin E in Cul3-deficient livers is not simply the result of increased cell proliferation (Supplemental Figure 2B).

Overexpression of cyclin $\mathrm{E}$ has been shown to induce DNA damage $(3,23)$, which can activate a p53-dependent checkpoint (24). To quantitate the extent to which progenitor cells and differentiated cells undergo DNA damage in response to the loss of Cul3 in vivo, we determined the levels of Ser139 phosphorylated histone $\mathrm{H} 2 \mathrm{AX}(\gamma-\mathrm{H} 2 \mathrm{AX})$, a marker for DNA double-strand breaks in livers from $\mathrm{Cul} 3^{\text {loxP/loxP }}$ AlfpCre mice, in wild-type livers and in livers expressing only the Cre recombinase, as embryonic fibroblasts from such mice were shown to display signs of DNA damage as a result of Cre recombinase expression (25). As shown in Figure 2B, $\gamma$-H2AX expression was detectable only in Cul3-deficient livers but not in wild-type livers or in mouse livers that express only the Cre recombinase. To confirm these results, we also performed Western blot analyses, as shown in Supplemental Figure 2C. We then performed costainings of stem cell markers and $\gamma$-H2AX to identify the cell type that showed the highest levels of DNA damage. For these experiments, 100 cells from 3-4 mice of each age group were scored. As shown in Figure 2C, only 20\% of the CD34-positive cells showed signs of DNA damage, while up to $70 \%$ of hepatocytes were positive for $\gamma$-H2AX. CK14-positive cells that had maintained the 
A
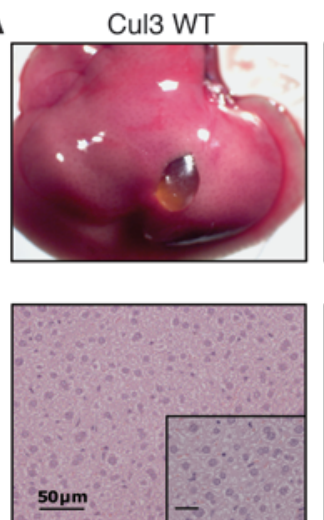

C
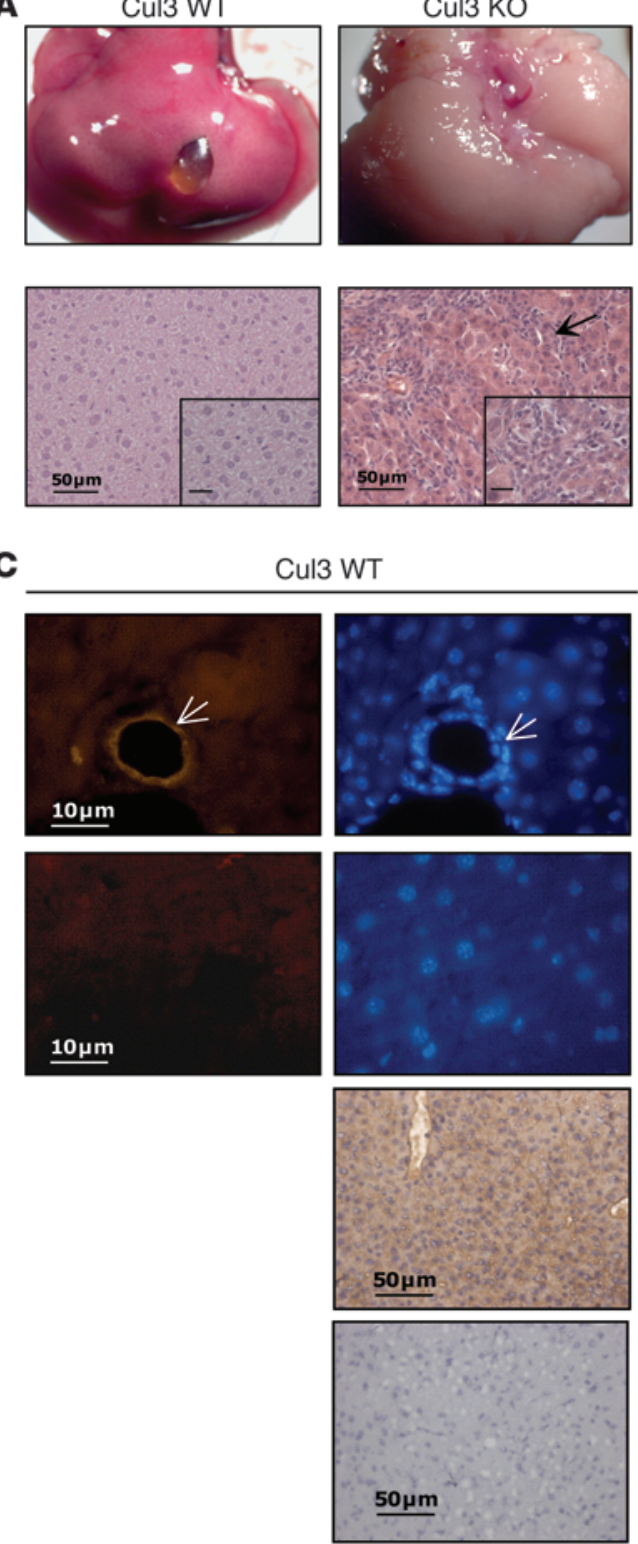

D

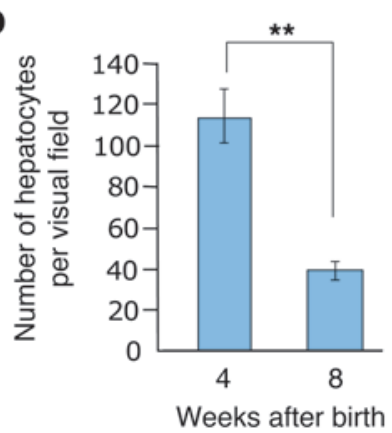

E
B

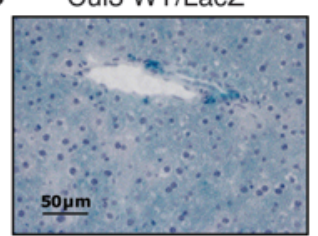

Cul3 WT/LacZ

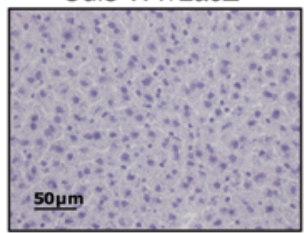

Cul3 KO

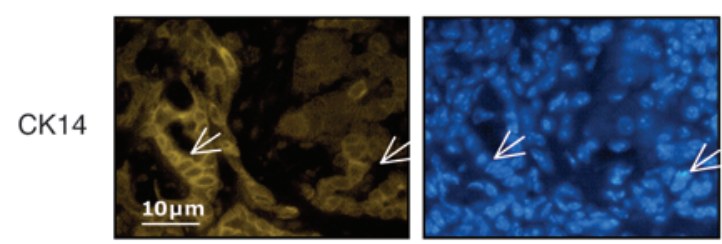

Albumin
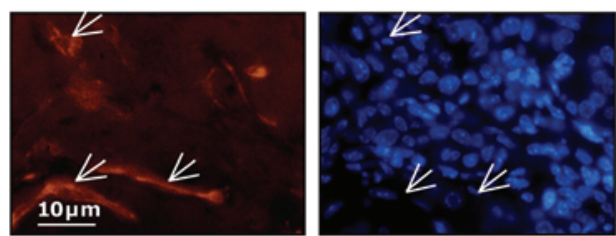

CD133
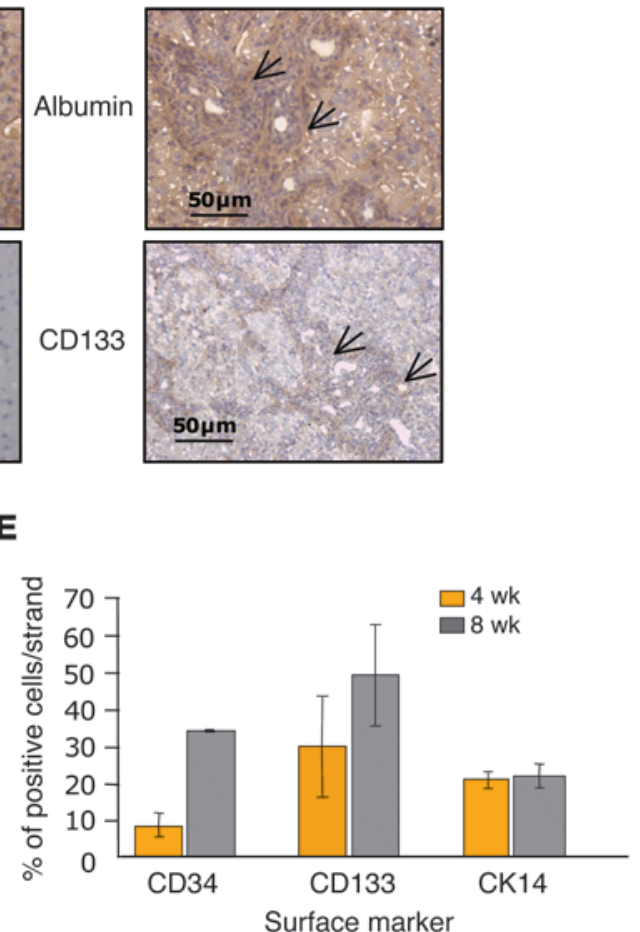


\section{Figure 1}

Loss of Cul3 leads to accumulation of hepatic progenitor cells in the liver. (A) Livers from Cul3loxP/loxP AlfpCre mice were harvested at 4 and 8 weeks after birth. The livers showed a pale discoloration and firm consistency. Upon microscopic analysis, hepatocytes could be distinguished from small mononucleated cells. Arrow indicates small mononucleated cells in strands (compare inset) that surround hepatocytic fields. (B) LacZ stainings in Cul3loxP/loxP AlfpCre Rosa26-LacZ mice were used to analyze the functionality of the Cre recombinase. Scale bars: $50 \mu \mathrm{m} ; 20 \mu \mathrm{m}$ (insets). (C) Immunofluorescence and immunohistochemical detection of progenitor-associated surface markers CK14, CD34 (first and third columns), and CD133. In wildtype livers, CK14-positive cells are primarily localized around bile ducts (compare arrows). CD34- and CD133-positive cells can only be found in Cul3-knockout livers (compare arrows that indicate positive cells in the strands). Cells also expressed the hepatocyte marker albumin. In the albumin staining, arrows indicate small mononucleated cells in the strands positive for albumin. Images in the second and fourth columns display the DAPI staining of the respective areas. Scale bars: $10 \mu \mathrm{m}$ (top panels); $50 \mu \mathrm{m}$ (bottom panels). (D) Quantification of hepatocytes in livers from Cul $3^{\text {loxP/loxp }}$ AlfpCre mice. H\&E sections and $\beta$-catenin stainings (compare Supplemental Figure 1E) were used to quantitate the number of hepatocytes in the livers. For each quantification, 3-4 mice were analyzed. (E) Quantification of progenitor cells positive for CD34, CD133, and CK14 at 4 and 8 weeks after birth. For each quantification, 3-4 mice were analyzed. ${ }^{*} P<0.005$.

small oval-shaped morphology (Figure 2D) showed intermediate levels of $\gamma$-H2AX positivity. In contrast, CK14-positive cells that were larger and more resembled liver cells accumulated DNA damage to the same extent as hepatocytes.

DNA damage can result in cellular responses such as apoptosis or cellular senescence $(26,27)$. In contrast to previous reports in which loss of the Fbw7 protein or stabilization of cyclin E resulted in a significant increase in apoptotic cell death $(7,10)$, we failed to detect increased numbers of apoptotic cells in Cul3 ${ }^{\text {loxP/loxP }}$ AlfpCre livers (data not shown) and therefore tested whether these cells might undergo senescence instead. As shown in Figure 2E, we found that $\mathrm{Cul} 3^{\text {loxP/loxp }}$ AlfpCre mice show strongly elevated levels of $\mathrm{p} 16^{\text {ink4a }}$ and $\mathrm{p} 15^{\mathrm{ink} 4 \mathrm{~b}}$ at 4 and 8 weeks after birth as compared with wildtype mice. In line with our finding that loss of Cul3 leads to DNA damage in differentiated cells, we found that CD34-positive cells were largely negative for the expression of the senescence associated marker p16, indicating that these cells are not affected by the loss of Cul3 (Figure $2 \mathrm{~F}$ ) and therefore did not undergo senescence in vivo. Together these results suggest that loss of Cul3 results in DNA damage in differentiated hepatocytes, which ultimately undergo senescence, while CD34-positive liver progenitor cells retain their proliferative potential and expand in number over time.

Induction of differentiation induces senescence and cell cycle exit in Cul3-deficient progenitor cells. To further analyze the relationship between senescence and differentiation in Cul3-deficient cells, we isolated Cul3-knockout cells from livers of Cul3 ${ }^{\text {loxP/loxP }}$ AlfpCre mice (see Methods for details). As shown in Supplemental Figure $3 \mathrm{~A}$, a shortened fragment $(\Delta 3-7)$ of the genomic Cul3 gene, in which exons 3-7 of the Cul3 gene were deleted, can be detected by RT-PCR in these cell lines. The isolated cell lines expressed the same stem cell markers as those detected in the Cul3 ${ }^{\text {loxP/loxP }}$ AlfpCre livers from which they originated (Supplemental Figure 3B). Because the CD34-positive fraction retained its proliferation capacity in vivo, we analyzed these CD34-positive cells in more detail. For this we separated the CD34-positive fraction from CD34-negative cells by cell sorting and determined the expression of different surface markers. As shown in Supplemental Figure 3C, CD34-positive cells were positive for c-kit and CK14 and expressed AFP, albumin, and the shortened version of the Cul3 transcript Cul3 $\Delta 3-7$. These cells are negative for CD133 and express CK19 at low levels. To date, we have derived a total of 5 independent Cul3-knockout lines and have maintained them in culture for more than 12 months.

Using these cell lines, we established an in vitro differentiation system to analyze the molecular mechanism involved in this process in isolated progenitor cells. For this, we treated Cul3-knockout cells with medium supplemented with different growth factors known to induce hepatic differentiation in vitro (28). As shown in Figure $3 \mathrm{~A}$, asynchronously growing Cul3-knockout cells expressed CD34 and AFP, indicative of their precursor status. Upon treatment with differentiation medium, both markers were no longer detectable by RT-PCR, while at the same time Cul3-knockout cells started to induce the expression of genes associated with hepatocellular differentiation. The hepatocyte-specific transcription factor PXR (29) was strongly induced at 48 hours after cultivation in differentiation medium, followed by the induction of liver-specific transcription factors such as HNF $1 / 4 \alpha$ and CCAAT enhancer binding protein $\alpha(\mathrm{C} / \mathrm{EBP} \alpha)$ and albumin (30) (Figure 3A). Importantly, upon differentiation, the vast majority of cells also changed their morphology from a small cell containing little cytoplasm to a cell that showed the typical hepatocyte morphology and glycogen deposition (Supplemental Figure 4A) (31). Next we determined the percentage of cells staining positive for $\gamma-\mathrm{H} 2 \mathrm{AX}$ in the differentiating cells as compared with asynchronously growing Cul3-deficient progenitor cells. As shown in Figure 3B, induction of differentiation led to a significant increase in the percentage of $\gamma-\mathrm{H} 2 \mathrm{AX}$-positive cells, while the number of proliferating cells as measured by BrdU uptake was simultaneously decreasing (Figure 3C). In line with the induction of senescence in Cul3-deficient livers in vivo, we found that 96 hours after the induction of differentiation, Cul3deficient cells ceased to proliferate and entered a senescent state as measured by $\beta$-galactosidase stainings, $\mathrm{p} 15^{\text {ink } 4 \mathrm{~b}}$ and $\mathrm{p} 16^{\text {ink } 4 \mathrm{a}}$ induction (Figure 3D and Supplemental Figure 4B), and accumulation of p53 (Supplemental Figure 4C). Given that the liver progenitor cells that we describe here only arise in Cul3-knockout livers, we decided to reconstitute Cul3 expression in the undifferentiated Cul3-deficient cells. Supplemental Figure 4, D and E, show that upon induction of differentiation, these cells do not accumulate DNA damage, nor do they become senescence.

Interestingly, we found that CD34 expression was reaccumulating at 72-96 hours after the induction of differentiation (Figure $3 \mathrm{~A}$ ), while expression of other stem cell markers such as CK14, c-kit, and CD133 decreased within this time course (Supplemental Figure 4F). To understand the reasons for the reaccumulation of CD34-positive cells, we pulse-labeled the cultures with BrdU and performed double labelings for BrdU and CD34. Upon induction of differentiation, we found a strong decrease in the number of CD34-positive cells that took up BrdU. Approximately $99 \%$ of the whole stem cell population was differentiating, and just a small fraction of CD34-positive cells remained in the cell cycle. At 72 hours and 96 hours, between $20 \%$ and $30 \%$ of the CD34-positive cells had reentered S phase as measured by BrdU uptake, which indicates that CD34-positive cells are able to resist differentiation-induced senescence (Figure 3E). As shown in Figure 3F, these reaccumulating CD34-positive cells did not show signs of DNA damage. 
A

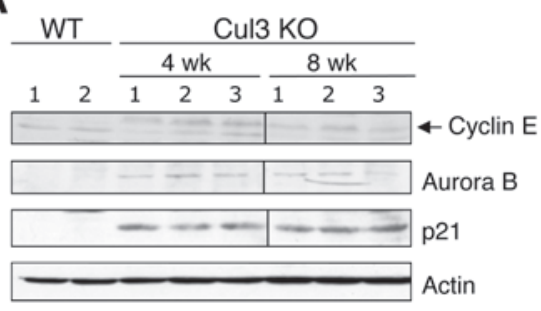

B

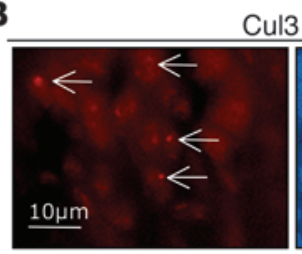

$\gamma-\mathrm{H} 2 \mathrm{AX}$

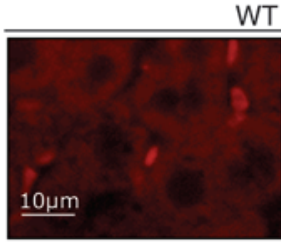

$\gamma-\mathrm{H} 2 \mathrm{AX}$

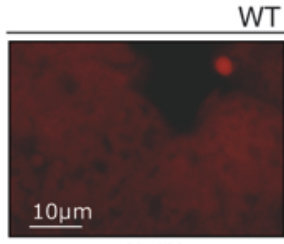

$\gamma-\mathrm{H} 2 \mathrm{AX}$

\section{ul3 KO}

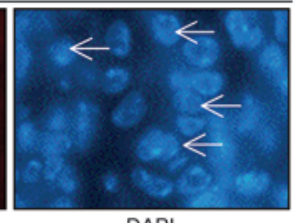

DAPI

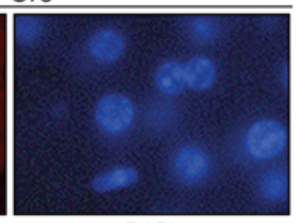

DAPI

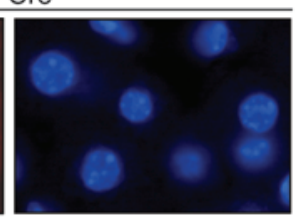

DAPI

C

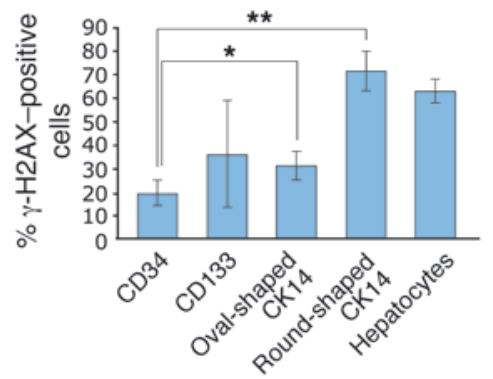

D

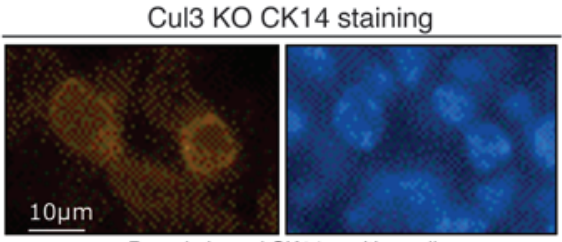

Round-shaped CK14-positive cells

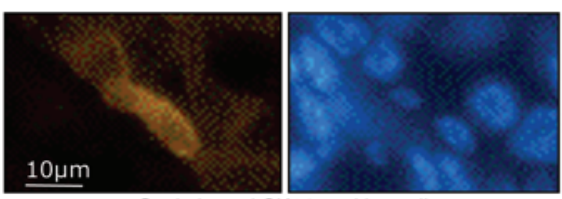

Oval-shaped CK14-positive cells

Cul3 WT CK14 staining

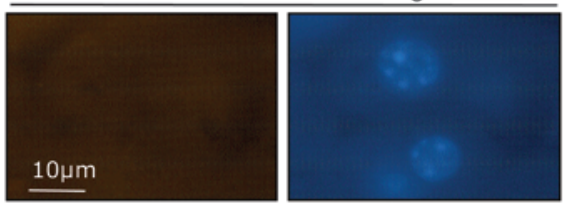

E

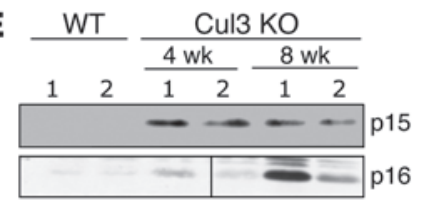

$\mathbf{F}$

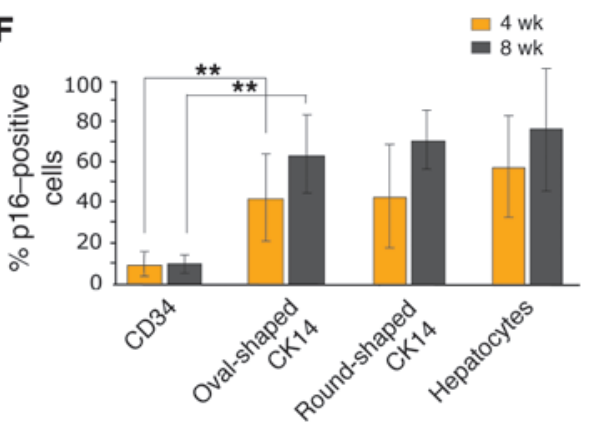

\section{Figure 2}

Differentiation of Cul3-knockout hepatic progenitor cells leads to the induction of DNA damage and cellular senescence. (A) Western blot analysis of known Cul3 substrates cyclin E, Aurora B, and p21 at 4 and 8 weeks after birth. Arrow indicates the cyclin $\mathrm{E}$ band. Actin was used as a loading control and was performed as noted in the methods section. Noncontiguous lanes from the same blot were spliced. Numbers indicate the different mice analyzed. (B) Immunofluorescence staining of $\gamma-\mathrm{H} 2 \mathrm{AX}$ in Cul3-knockout and wild-type mice positive and negative for Cre recombinase. Arrows in Cul3loxP/loxP AlfpCre (Cul3 KO) livers indicate cells that accumulated DNA damage. In wild-type $\mathrm{Cre}^{+}$and $\mathrm{Cre}^{-}$ livers, no $\gamma-\mathrm{H} 2 \mathrm{AX}$ (left panels) staining can be detected (compare Supplemental Figure 2C). DAPI staining is shown in the right panels. (C) Quantification of DNA damage in CD34-, CD133-, and CK14-positive cells (at least 100 cells from 3-4 mice were analyzed). The graph shows quantification of double-positive cells. (D) Representative pictures of round- and oval-shaped CK14-positive cells (left panels). DAPI is shown in the right panels. CK14positive cells cannot be found in wildtype livers. (E) Western blot analysis for senescence-associated markers p15 and p16 in whole liver lysates in Cul3loxP/loxp AlfpCre livers at 4 and 8 weeks after birth in comparison with wild-type liver lysates, in which no p15 or $p 16$ could be detected. Numbers indicate the different mice analyzed. Noncontiguous lanes from the same blot were spliced. (F) Quantification of the expression of p16 in different liver cells at 4 and 8 weeks (200 CD34- or CK14-positive cells in 3 independent experiments). Hepatocytes were identified by typical morphology (Supplemental Figure 1E). Scale bars: $10 \mu \mathrm{m}$. ${ }^{\star} P<0.05,{ }^{* \star} P<0.005$.
These in vitro findings therefore recapitulate our observation in the Cul3-knockout mice in vivo, namely that CD34-positive Cul3deficient cells are resistant to the differentiation-induced DNA damage that forces the remainder of the population into senescence.

Cyclin E turnover is differentially regulated in liver progenitor cells and hepatocytes. Cyclin E turnover requires the activity of the BCR ubiquitin ligase. Our results regarding the induction of DNA damage in differentiated cells but not in hepatic progenitor cells suggested that the dependency on Cul3 activity depends on the differentiation stage of the cell. We therefore determined the half-life of cyclin $\mathrm{E}$ in asynchronously growing cells and compared it with the half-life of cyclin $\mathrm{E}$ in differentiating Cul3-deficient cells. As shown in Figure 4A, cyclin E had a half-life of approximately
5 hours in asynchronously proliferating cells, while 24 hours after induction of differentiation, cyclin $\mathrm{E}$ was no longer degraded. In contrast, reexpression of $\mathrm{Cul} 3$ resulted in normal degradation of cyclin E (Supplemental Figure 4G), leading to a decrease in overall cyclin E levels after 48 hours of differentiation (Supplemental Figure $4 \mathrm{E}$ ). This indicates that the loss of Cul3 prevents the turnover of cyclin E specifically in differentiating cells.

As asynchronously growing Cul3-deficient cells showed no signs of DNA damage, we wondered whether these cells might be resistant to cyclin E-induced DNA damage or might not be able to respond to genotoxic stress altogether. However, after transfecting Cul3deficient cells with a cyclin E-expressing plasmid, we detected signs of DNA damage ( $\gamma$-H2AX positivity) in the cyclin E-overexpressing 
A

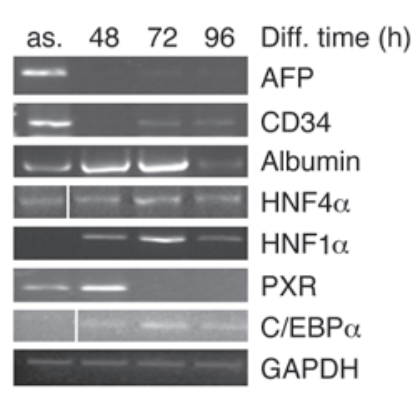

D
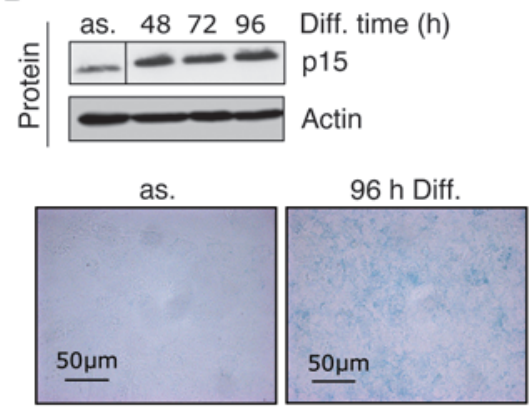

$\beta$-gal staining

F

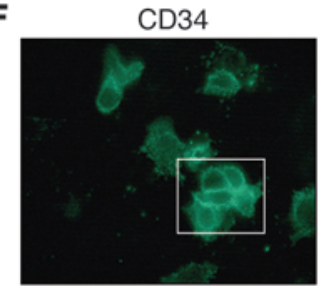

B

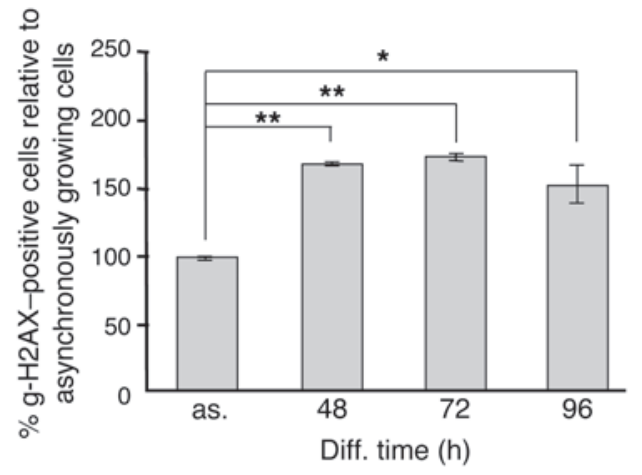

E
C

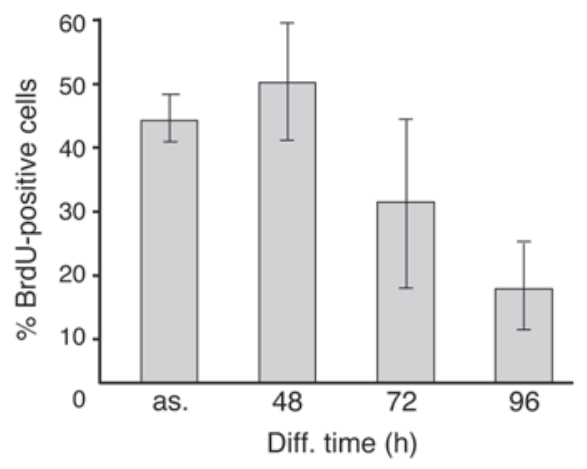

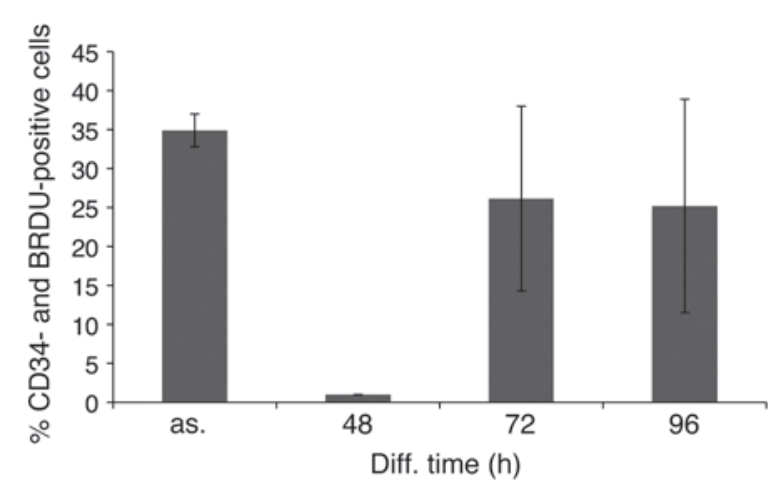
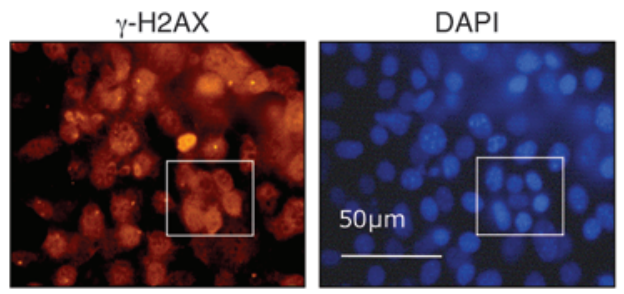

Figure 3

In vitro differentiation of progenitor cells recapitulates the in vivo phenotype. (A) RT-PCR analysis of progenitor cell- and hepatocyte-specific markers in asynchronous (as) cells and at different time points during differentiation (Diff.). Noncontiguous lanes from the same gel were spliced. (B) Quantitation of $\gamma-\mathrm{H} 2 \mathrm{AX}$ staining by immunofluorescence at the indicated time points after the induction of differentiation. At least 3 independent experiments were analyzed. Asynchronously growing cells were set as $100 \%$. (C) Quantitation of cells in S phase by BrdU uptake (experiments were performed in triplicate). (D) Hepatic progenitor cells induce senescence upon differentiation. Western blot analysis during differentiation shows a strong accumulation of the senescence-associated marker p15. Progenitor cells from Cul3loxP/loxP AlfpCre mice stain positive for $\beta$-galactosidase at $\mathrm{pH} 5.8$ at 96 hours after the induction of differentiation. All experiments were repeated 3-4 times. Actin was used as a loading control and analysis performed as noted in Methods. Noncontiguous lanes from the same blot were spliced. (E) Analysis of proliferation of CD34-positive cells during differentiation by quantification of CD34/BrdU. Proliferation of CD34-positive cells in asynchronously growing culture is also shown $(n=2)$. (F) Immunofluorescence $\gamma$-H2AX staining of CD34-positive cells at 96 hours of differentiation. Squares indicate CD34-positive cells, showing that these do not accumulate DNA damage. Scale bars: $50 \mu \mathrm{m} .{ }^{*} P<0.05,{ }^{* \star} P<0.005$.

Cul3-negative cells (Figure 4B). We were also able to induce DNA damage and phosphorylation of Chk1 when we treated Cul3knockout progenitor cells with the DNA-damaging agent $\mathrm{H}_{2} \mathrm{O}_{2}$ in vitro (Figure 4C) or injected Cul3 $3^{\text {loxp/loxP }}$ AlfpCre mice with doxorubicin (Supplemental Figure 5A), indicating that DNA damage response mechanisms are intact in Cul3-deficient progenitor cells.

These data suggested that the activity of the Cul3-dependent BCR E3 ligase is dispensable in progenitor cells but that cyclin E levels still need to be tightly controlled. We therefore wondered whether loss of the FBW7-dependent Skp1, Cullin1, F-box protein contain- ing complex (SCF ${ }^{\mathrm{FBW}}$ ) E3 ubiquitin ligase might affect cyclin $\mathrm{E}$ levels and genetic stability in these cell lines. Knockdown of Fbw7 or Cul1, components of the Fbw7-dependent SCF complex in asynchronously growing Cul3-deficient cells, led to a complete stabilization of cyclin E (Figure 4D). The knockdown was confirmed by RT-PCR (Figure 4E). Importantly, these cells also showed signs of DNA damage upon loss of Fbw7 or Cul1 (Figure 4F). To determine whether the accumulation of cyclin $\mathrm{E}$ was indeed responsible for the observed induction of DNA damage, we transfected Cul3-deficient progenitor cells with siRNAs targeting cyclin E1 and cyclin E2 and 


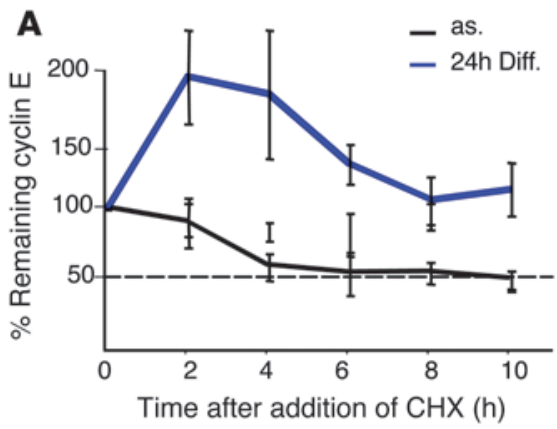

C

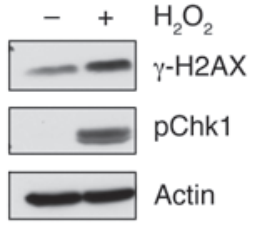

D

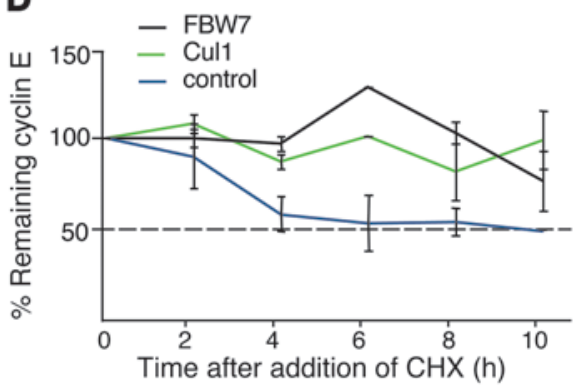

B
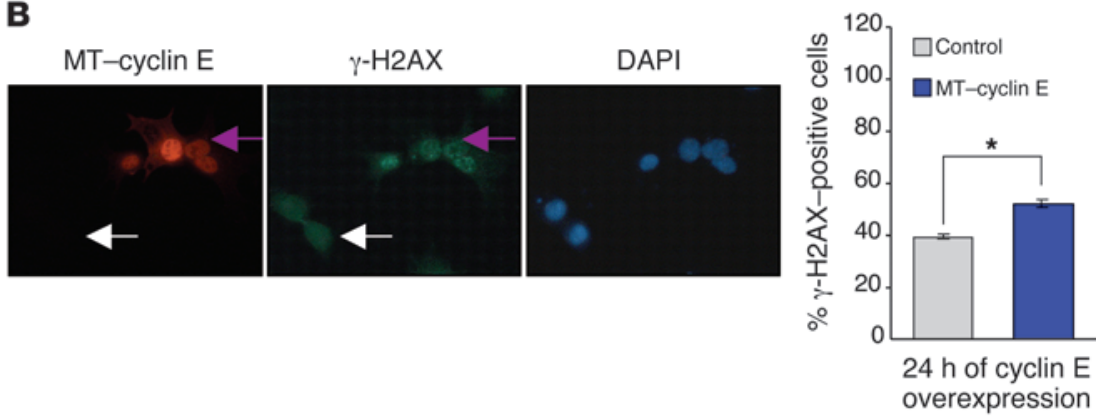

E

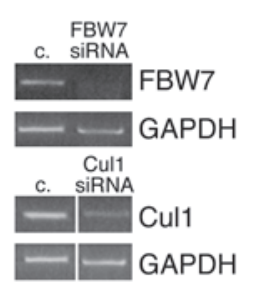

F

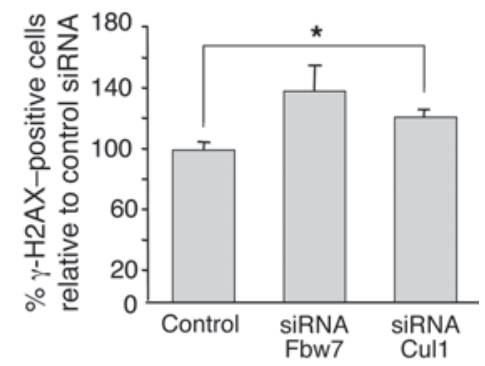

G

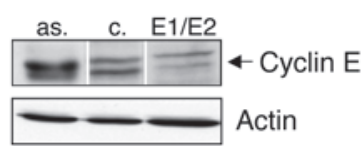

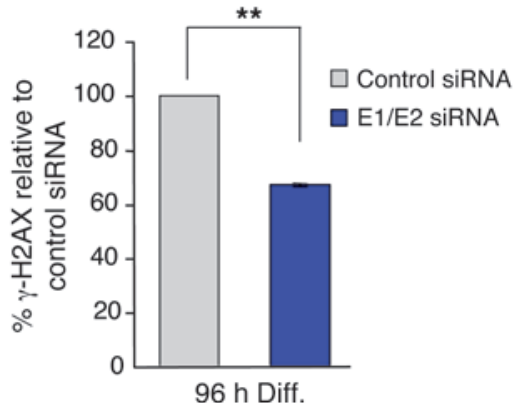

H

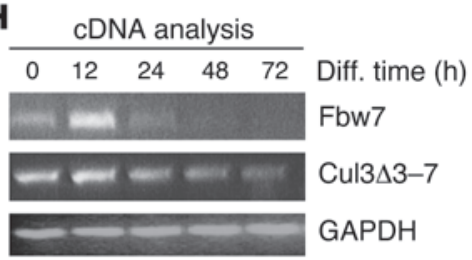

Figure 4

Accumulation of cyclin $\mathrm{E}$ in differentiating hepatic progenitor cells is responsible for the accumulation of DNA damage. (A) Cyclin E half-lives during differentiation and in asynchronously proliferating cells. At 24 hours of differentiation, cyclin E accumulates (experiments were performed in triplicate). (B) Overexpression of myc-tagged cyclin $\mathrm{E}$ in asynchronously growing cells from Cul3loxP/loxP AlfpCre mice and quantitation of DNA damage $(\gamma-\mathrm{H} 2 \mathrm{AX})$. Immunofluorescence for myc tagged (MT)-cyclin E, $\gamma-\mathrm{H} 2 \mathrm{AX}$, and DAPI. Arrows indicate cyclin E-overexpressing cell positive for $\gamma-\mathrm{H} 2 \mathrm{AX}$ (pink arrow) and an untransfected cell (white arrow) $(n=3)$. (C) Treatment of cells from Cul3loxP/loxP AlfpCre mice with $\mathrm{H}_{2} \mathrm{O}_{2}$ and analysis of DNA damage by $\gamma-\mathrm{H} 2 \mathrm{AX}$ and pChk1 Western blots. (D) Measurement of cyclin E half-lives upon siRNA-mediated knockdown of Fbw7 and Cul1 in asynchronously proliferating cells. Loss of Fbw7 and Cul1 increases cyclin E protein stability ( $n=3$ /experiment). CHX, cycloheximide. (E) Confirmation of siRNA-mediated knockdown by RT-PCR. GAPDH was used as control. Noncontiguous lanes from the same gel were spliced. (F) Increased DNA damage as measured by $\gamma-\mathrm{H} 2 \mathrm{AX}$ staining upon knockdown of Fbw7 and Cul1. For identification of transfected cells, a labeled siRNA control was cotransfected. (G) siRNA-mediated knockdown of cyclin E during differentiation and determination of DNA damage $(\gamma-\mathrm{H} 2 \mathrm{AX})$. Knockdown of cyclin E was confirmed by Western blotting. The arrow indicates the cyclin E band. c., scrambled siRNA control. Actin was used as a loading control and analysis performed as noted in Methods. Noncontiguous lanes from the same blot were spliced. The graph shows quantification of $\gamma$-H2AX-positive cells transfected with the indicated siRNAs 96 hours after the induction of differentiation $(n=3)$. (H) RT-PCR analysis of Fbw7 and Cul3 $\Delta 3-7$ expression during differentiation of progenitor cells into hepatocytes at indicated time points. GAPDH was used as a control. ${ }^{*} P<0.05$.

determined the number of $\gamma$-H2AX-positive cells. The knockdown of the cyclin E protein was confirmed by Western blotting. While differentiating Cul3-knockout cells still underwent DNA damage, we found that knockdown of cyclin E led to a significant reduction in the number of cells showing DNA damage as compared with untransfected controls (Figure 4G). Our data suggest that loss of $\mathrm{Cul3}$ in progenitor cells is not sufficient to induce cyclin E-dependent DNA damage or interfere with the ability of liver progenitor cells to self-renew. These undifferentiated cells nevertheless need to control cyclin E stability through the activity of the $\mathrm{SCF}^{\mathrm{Fbw}}$ 7 E3 ubiquitin ligase. However, upon induction of differentiation, Cul3 activity becomes critical, which then forces the Cul3-deficient cells to activate their DNA damage response and exit the cell cycle. These results suggested that the $\mathrm{SCF}^{\mathrm{Fbw}}{ }^{7} \mathrm{E} 3$ ubiquitin ligase and the $\mathrm{BCR}$ ubiquitin ligase must be differentially regulated in liver progenitor and differentiating cells. In line with this conclusion, we found that Fbw7 transcripts are strongly downregulated in differentiating liver progenitor cells (Figure 4H). Fbw7 expression decreases significantly between 12 and 24 hours of differentiation (compare also Supplemental Figure 5B). Conversely, the shortened message 
A

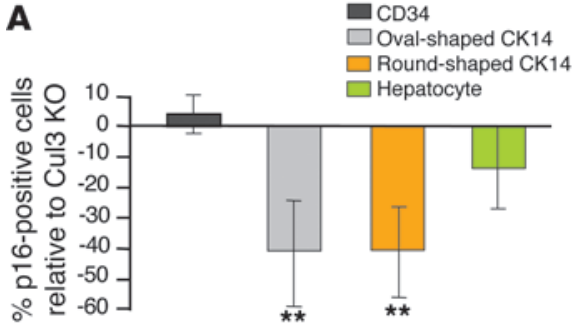

C

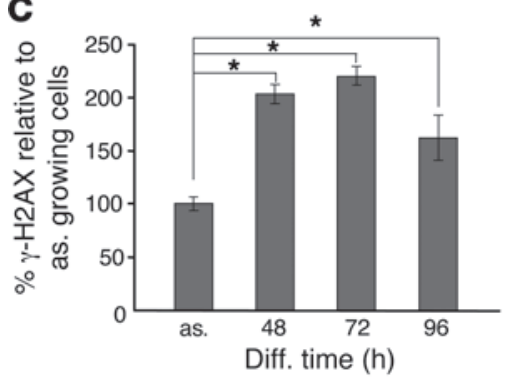

B

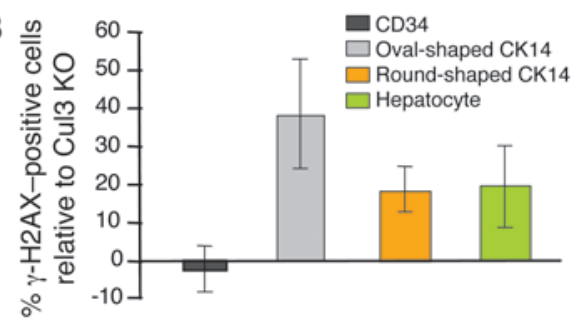

D

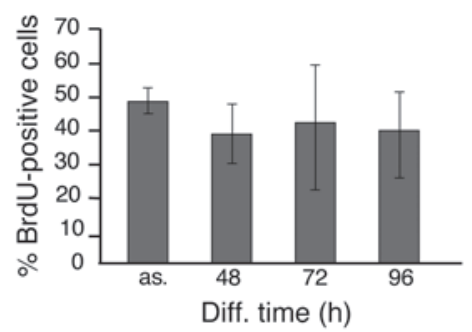

E
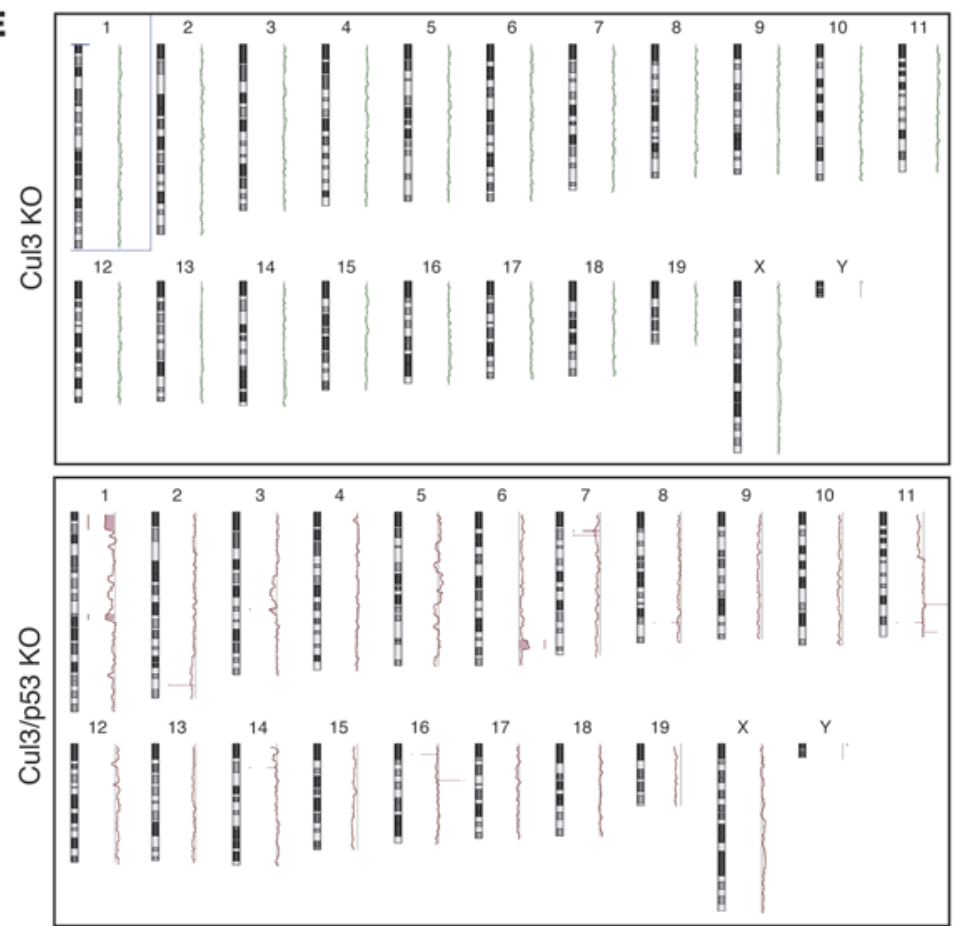

Figure 5

Maintenance of senescence by p53 is essential for preventing the generation of tumor-initiating stem cells. (A) Quantitation of p16 expression in the indicated liver cells from Cul3/p53 double-knockout animals at 10-11 weeks after birth. Values are shown as difference relative to p16-positive cells in livers from Cul3 single-knockout animals (compare Figure 2F) ( $n=3 /$ group). (B) Quantitation of $\gamma$-H2AX expression in the indicated liver cells from Cul3/p53 double knockout animals at $10-11$ weeks after birth. Values are shown as difference relative to $\gamma-\mathrm{H} 2 \mathrm{AX}$-positive cells in livers from Cul3 single-knockout animals (compare Figure 2C) ( $n=3$ /group). (C) Quantitation of $\gamma-\mathrm{H} 2 \mathrm{AX}$ staining by immunofluorescence at the indicated time points after the induction of differentiation. Asynchronously growing cells were set as $100 \%$. (D) Quantitation of S-phase cells by BrdU uptake at the indicated time points after the induction of differentiation. (E) Comparative genomic hybridization analysis of $\mathrm{Cul} 3$ and Cul3/p53 double-knockout cells after induction of differentiation for 96 hours compared with undifferentiated cells of the identical genotype. ${ }^{\star} P<0.05,{ }^{*} P<0.005$. derived from the deleted Cul3 locus (Cul3 $\Delta 3-7)$ is constitutively expressed under these conditions (Figure $4 \mathrm{H}$ ) and declined only to about $60 \%$ but then remained constant (compare also Supplemental Figure 5B). In accordance with the downregulation of Fbw7, we found Cul1, the E3 ligase component for the F-box protein Fbw7, also to be downregulated between 48 and 96 hours of differentiation (Supplemental Figure 5C).

The loss of Cul3 therefore becomes critical only under conditions of cellular differentiation, at which point the differentiated cells are undergoing DNA damage-induced senescence. We therefore next asked whether the inactivation of the DNA damage response pathway might convert the Cul3 deficient nontumorigenic progenitor cells into tumor cells.
Loss of 53 collaborates with Cul3 deficiency to induce highly malignant tumor stem cells. The p53 protein is an important regulator of cellular senescence and is also frequently mutated in human liver cell cancers (32). To analyze its role in the differentiation-induced senescence pathway, we crossed the Cul3 ${ }^{\text {loxP/loxP }}$ AlfpCre mice to a $53^{\text {loxP/loxp }}$ mouse strain (33). As shown in Supplemental Figure $6 \mathrm{~A}, \mathrm{Cul3} / \mathrm{p} 53^{\text {loxP/loxp }}$ AlfpCre double-knockout livers showed similar changes in liver architecture: residual hepatocytes and an accumulation of small mononucleated cells expressing the same markers as Cul3 ${ }^{\text {loxP/loxP }}$ AlfpCre livers (Supplemental Figure 6, B, $\mathrm{D}$, and $\mathrm{E}$ ). To test whether the induction of senescence observed in the Cul3-deficient livers is dependent on the expression of p53, we measured the expression of $\mathrm{p} 16^{\text {ink4a }}$ in primary liver tissue 
A

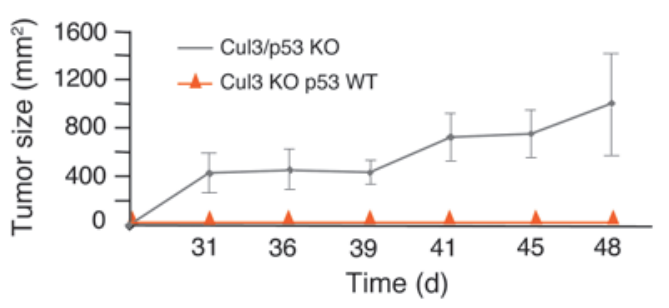

B

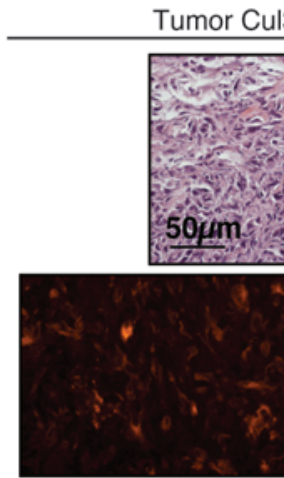

CK14

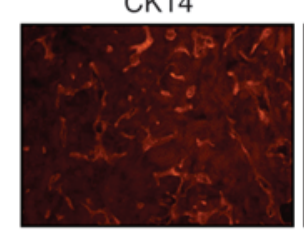

CD34
C

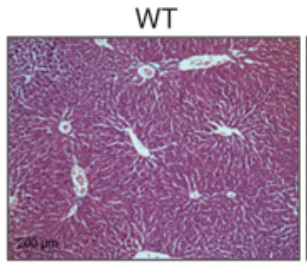

Cul3 KO

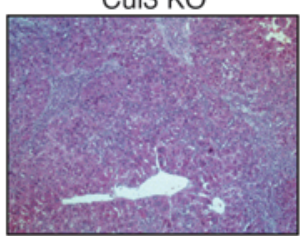

D
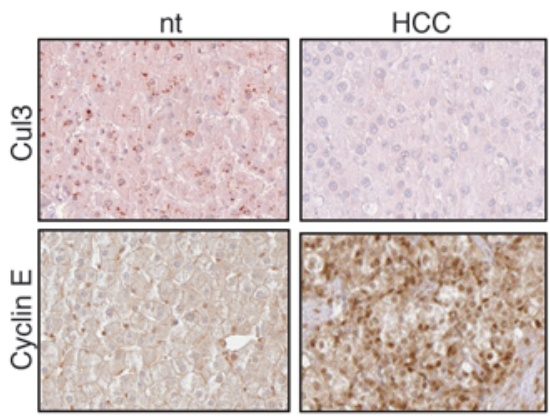

E

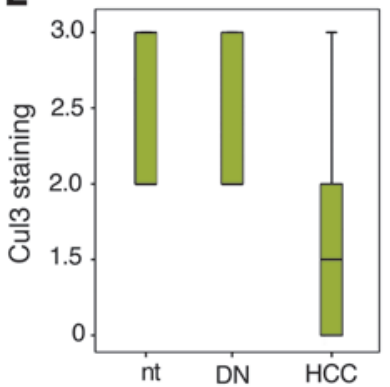

Cul3/p53 KO

\section{.}
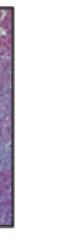

(

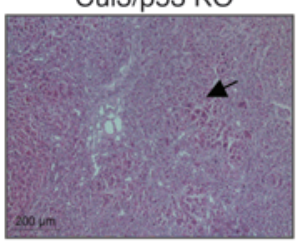


We did, however, detect a strong increase in the number of CK14 cells that stained positive for $\gamma$-H2AX (Figure 5B). In line with these in vivo results, we found that isolated Cul3/p53 doubleknockout progenitor cells showed signs of DNA damage (Figure 5C) upon induction of differentiation (Supplemental Figure 5D) but in contrast to Cul3 single-knockout cells failed to exit the cell cycle, as shown in Figure 5D. Together these results indicate that induction of $\mathrm{p} 53$ prevents cell cycle progression in differentiating Cul3-deficient CK14-positive progenitor cells and forces these cells into senescence.

To further substantiate these findings with regard to the formation of human liver cancers, we tested the role of $\mathrm{Cul} 3$ in the prevention of DNA damage and the induction of senescence markers in human liver cancer cell lines. As shown in Supplemental Figure $7 \mathrm{~A}$, a reduction in the expression of Cul3 in HepG2 cells through siRNA treatment led to an increase in the number of CD133-positive cells of about $25 \%$. Loss of Cul3 was confirmed by RT-PCR (Supplemental Figure 7B). Moreover, asynchronously growing human CD133-positive cells in which Cul3 expression was decreased by siRNA treatment showed an increase in the S-phase fraction as measured by BrdU uptake when compared with control siRNA-treated CD133-positive cells (Supplemental Figure 7A).

HepG2 cells started to express liver differentiation markers such as HNF4 $\alpha$ when treated with differentiation medium (Supplemental Figure 7C), while at the same time expression levels of Fbw7 were decreasing and expression levels of Cul3 were increasing. Next we tested whether loss of Cul3 during differentiation would lead to the induction of DNA damage as measured by the expression of $\gamma-\mathrm{H} 2 \mathrm{AX}$ and induction of senescence markers. Supplemental Figure 7D shows that Cul3-deficient human cells indeed undergo DNA damage and start to express p 15 after induction of differentiation.

As our studies in Cul3-deficient mouse liver progenitor cells suggested that differentiation-induced DNA damage and senescence lead to the activation of a p53-dependent DNA damage response, we compared CD133-positive cells derived from a p53-positive (HepG2) cell line with CD133-positive cells that express a mutant version of p53 (HUH7). As shown in Supplemental Figure 7, E and F, only the p53 wild-type CD133-positive cells ceased to proliferate after the induction of differentiation, while p53 mutant CD133positive cells continued to take up BrdU. Together these findings support our finding derived from the study of Cul3-deficient mouse liver progenitor cells, namely that the expression of Cul3 is required to prevent the formation of genetically unstable cells after the induction of differentiation.

Genetic instability is a hallmark of liver cancer development and increases as the tumor de-differentiates (34). To test whether the observed induction of double-strand breaks in differentiating Cul3-deficient hepatocytes would lead to the formation of genetically unstable cells, we performed comparative genomic hybridization analysis in Cul3 single- and Cul3/p53 double-knockout cells and compared their genetic composition before and after the induction of differentiation. Figure 5E shows that while Cul3knockout cells remained genetically stable, loss of p53 resulted in the induction of multiple chromosomal rearrangements as early as 96 hours after the induction of differentiation.

Cul3 is expressed at low levels in hepatocellular carcinomas. Our data show that loss of Cul3 predisposes hepatic progenitor cells to the induction of DNA damage. However, the induction of a p53dependent senescence mechanism blocks the proliferation of such cells, which limits their tumorigenic potential. In line with this conclusion, we found that Cul3-deficient hepatic progenitor cells fail to form tumors in nude mice, as shown in Figure 6A. We found that in contrast to the Cul3 single-knockout cells, all of the Cul3/p53 double-knockout lines we isolated formed tumors after transplantation into nude mice (Figure 6A). Importantly, as few as $100 \mathrm{Cul3/p53}$ double-knockout progenitor cells were sufficient to form tumors $\left(700-800 \mathrm{~mm}^{3}\right)$, with a latency of approximately 70 days. Remarkably, the tumors generated by these cells did not grow in a confined position under the skin of the mouse, but often also infiltrated into the supporting muscle layers and into the peritoneal cavity.

Upon histological examination, we found highly malignant anaplastic tumors displaying variable aspects of hepatic and cholangiocytic development (Figure 6B). Immunohistochemical analysis revealed cells that were positive for $\mathrm{CD} 34$ but also large areas that did not stain for this marker, indicating the differentiation potential of the Cul3/p53 double-knockout cells from which the tumor originated. Next we tested whether loss of p53 in a Cul3-deficient mouse liver would also result in the formation of primary liver cell carcinomas. Microscopic examination of the Cul3/p53 doubleknockout livers at 11 weeks after birth revealed the presence of hepatocellular carcinomas in these mice, while none of the Cul3 single-knockout mice developed liver tumors during their life span (Figure 6C). It is, however, important to note that the overall life span of the Cul3/p53 double-knockout mice was not different from that of the Cul3-knockout mice, indicating that the severe disruption of liver architecture was most likely responsible for the death of these animals and prevented the formation of large, macroscopically visible liver cancers.

Based on our findings in the Cul3 mouse model, we asked whether loss of Cul3 expression might also contribute to liver carcinogenesis in humans. We therefore analyzed the expression levels of Cul3 in normal human liver tissue $(n=42)$, dysplastic liver nodes $(n=9)$, and malignant human liver cancers $(n=62)$. Given the importance of cyclin E dysregulation for the observed phenotypes in our mouse model, we also stained these tissues with antibodies specific for cyclin E. A representative example of these immunohistochemical stainings is shown in Figure 6D. A quantification of the results of this analysis is shown in Figure $6 \mathrm{E}$, in which $\mathrm{Cul} 3$ expression levels were assigned scores ranging from 0 (no expression) to 3 (strong expression). This analysis revealed that in contrast to normal liver tissue or dysplastic nodes, tumor tissues expressed greatly reduced levels of Cul3 $(r=-0.375$; $P=0.0001$ ). Conversely the expression levels of cyclin E were very low in normal liver tissue but significantly increased in tumor tissues. Moreover, the increase in cyclin E protein levels and decrease in Cul3 protein levels correlated significantly upon de-differentiation of tumors $(r=-0.476, P=0.046)$. Finally, we tested whether the observed correlation between Cul3 expression and differentiation was specific to hepatocellular carcinomas or whether similar changes could be observed in cholangiocellular carcinomas as well. For this we analyzed Cul3 expression in cholangiocellular carcinomas using 67 CCC G2 and 84 CCC G3 tumors. In contrast to hepatocellular carcinomas, expression levels of $\mathrm{Cul} 3 \mathrm{did}$ not correlate with the de-differentiation process in cholangiocellular carcinomas when compared with Cul3 expression levels of normal cholangiocytes or of normal liver tissue (Supplemental Figure $6 \mathrm{G}$ ). The role of Cul3 in tumorigenesis of the liver therefore seems to be restricted to hepatocellular carcinomas. 


\section{Discussion}

In this work we provide a mechanistic framework for explaining how highly malignant liver cancers can arise from liver stem cells. We tested the importance of reduced Cul3 expression for liver tumorigenesis in a mouse model that allows the tissue-specific ablation of the Cul3 gene. Using this model system, we show that loss of the Cul3-based degradation system has two important effects that promote the generation of liver tumors. First, it prevents the development of mature hepatocytes from hepatic progenitor cells. It is important to note that the block to differentiation we observe in Cul3-deficient cells is not caused by a defect in a differentiation pathway but is instead a result of the activation of DNA damage response mechanisms specifically in differentiating but not in progenitor cells. Due to the existence of a redundant cyclin E ubiquitin ligase, the $\mathrm{SCF}^{\mathrm{Fbw} 7}$ complex, progenitor cells are protected from the DNA damage-inducing activity of cyclin E accumulation. This difference in sensitivity to loss of Cul3 and therefore induction of DNA damage positively selects for the expansion of immature progenitor cells but drives differentiating cells into senescence. Nevertheless, this mechanism would arrest the development of Cul3-deficient progenitor cells by negatively selecting against the differentiated offspring. It is also interesting to note that while both cyclin E ubiquitylation complexes are expressed in undifferentiated mouse liver progenitor cells, only the $\mathrm{SCF}^{\mathrm{Fbw} 7}$ system is required for cyclin E turnover in these cells. Upon induction of differentiation toward mature hepatocytes, Fbw7 expression is transcriptionally downregulated. It is unknown why during liver cell differentiation a switch between the Fbw7-and the Cul3-dependent degradation systems occurs or which transcription factors might influence the expression of the Fbw 7 gene. However, dual regulation of a substrate by SCF and Cul3-dependent degradation systems is not without example, as recent work demonstrates that the transcription factor cubitus interruptus, which is the downstream target of Hedgehog signaling, is degraded by SCF Slimb/beta-TRCP and a Cul3-HIB-dependent E3 ubiquitin ligases $(13,35)$. Interestingly, in eye imaginal discs, where Hedgehog signals coordinate cell proliferation and differentiation, the BTB protein HIB is highly expressed in the differentiating cells to prevent aberrant Hedgehog signaling activity and ensure normal eye development (35).

In addition to the differential effect the loss of Cul3 has on the induction of genetic damage in progenitor versus differentiated cells, its expression is critical for the ability of the differentiating cell to proliferate. In this work we show that after induction of differentiation, CD34-positive Cul3-deficient cells rapidly cease to proliferate and undergo senescence in vitro. This response depends on the induction of the p53 tumor suppressor protein. As we were unable to identify liver cancers in Cul3-deficient mouse livers or after transplantation of Cul3-deficient cells into nude mice, we conclude that the differentiation-induced senescence checkpoint efficiently protects from the development of liver cancer. However, loss of p53 is one of the most frequent genetic defects identified in human hepatocellular carcinomas (32). Specifically, long-standing liver inflammation, aflatoxin intoxication, and viral hepatitis-associated liver cancer are frequently associated with defects in the p53 tumor suppressor protein. We therefore tested whether the loss of Cul3 in hepatic progenitors would synergize with loss of p53 in the induction of hepatocellular carcinoma. Indeed, we found that loss of p53 completely abrogated the differentiation-induced senescence response of Cul3-deficient hepatic progenitors. Alternatively, Cul3/p53-deficient progenitor cells could undergo senescence in response to DNA damage but then due to the loss of p53 escape the senescence response and reenter the cell cycle. Our in vitro data, however, do not argue for such a mechanism, as in contrast to the Cul3-deficient cells, the Cul3/p53 double-knockout cells did not exit the cell cycle in response to the induction of differentiation. It is interesting to note that the induction of $\mathrm{p} 21$ is most likely not responsible for the observed cell cycle arrest in Cul3-deficient cells, as the Cul/p53 double-knockout cells also showed increased levels of $\mathrm{p} 21$. The connection between the p53- and the p15/p16-dependent signaling pathways therefore seems to be responsible for the observed changes in proliferation in the different mouse lines.

Importantly, not only did the Cul3/p53-deficient cells lose their ability to undergo cell cycle arrest, they also displayed severe chromosomal alterations that were detectable as early as 96 hours after the induction of differentiation. Loss of p53 in differentiating Cul3-deficient progenitor cells therefore promotes the formation of highly malignant genetically unstable cancer cells. These cells display several features of cancer-initiating cells. After transplantation into nude mice, they form tumors at very low cell numbers. As few as $100 \mathrm{Cul3/p53-deficient} \mathrm{cells} \mathrm{were} \mathrm{sufficient} \mathrm{to} \mathrm{form} \mathrm{cancers}$ in this model and were serially transplantable. Histological and immunohistochemical analysis of these tumors revealed highly pleomorphic tumors, which in addition to containing tumor cells that showed features of hepatocytic differentiation also contained the CD34-positive progenitor cells from which they originated.

Expansion of the number of liver progenitor cells that then differentiate into mature hepatocytes is best characterized in animal models in which normal liver cell proliferation is blocked (36). Under such conditions, bipotential liver progenitor cells will expand in number and help to repopulate the damaged organ. This continuous proliferation will ultimately exhaust the regenerative potential of the mature hepatocytes and thus induce a compensatory expansion of progenitor cells that attempt to replace damaged liver cells. We hypothesize that Cul3-deficient hepatic progenitor cells reside in the liver over a long period of time but only attempt to expand and differentiate into hepatocytes when the regenerative capacity of the liver is exhausted. Therefore, only when hepatocyte-based liver regeneration is sufficiently impaired do liver progenitor cells receive sufficient external signals to undergo differentiation. While liver cirrhosis is known to be a prerequisite for the formation of genetically altered hepatocytes that ultimately give rise to tumors, it might also be necessary for the formation of stem cell-derived liver cancers. This idea could explain why most liver cancers, even those with histologic features of stem cells, originate from cirrhotic livers.

The model that arises from our study predicts that defects such as the loss of Cul3 will lead to severe genetic damage in differentiated cells but not in progenitor cells from which these cells originate. This difference is based on the differential expression of the $\mathrm{SCF}^{\mathrm{Fbw} 7}$ and Cul3-BTB dependent ubiquitin ligases and selects for the expansion of undifferentiated progenitor cells while the differentiated offspring undergo senescence. Cul3-deficient progenitor cells can persist in the liver only in their undifferentiated state but carry a high risk of malignant transformation. A second genetic alteration, such as the loss of p53, which is essential for maintaining the senescence response activated by the loss of Cul3 in differentiated cells, is sufficient to transform these cells into highly malignant tumor-initiating cells. In summary, our data provide 
the framework for the identification of genes that by connecting differentiation and DNA damage responses in stem or progenitor cells allow for the formation of tumor-initiating cells.

\section{Methods}

Mouse work and tumor studies. All experiments were performed with the approval of the animal rights and protection agencies Niedersächsisches Landesamt für Verbraucherschutz und Lebensmittelsicherheit, Lower Saxony, Germany. Livers of Cul3 ${ }^{\text {loxP/loxP }}$ AlfpCre and Cul3/p53 loxP/loxP AlfpCre mice were harvested at 4 and 8 weeks after birth. DNA, RNA, and protein extractions were done as previously described (37). Tumor studies were done as previously described (38). Tumor growth was determined for 6 tumors of 3 mice for each genotype. To determine the minimum number of cells able to form a tumor in nude mice, Cul3/p53 hepatic progenitor cells were serially diluted to 100 cells per injection.

To analyze liver regeneration, we mixed $\mathrm{CCl}_{4}$ 1:4 with mineral oil and injected $3.5 \mu \mathrm{l} / \mathrm{g}$ mouse intraperitoneally. After 48 hours, BrdU was injected 2 hours before sacrifice. Livers were harvested and fixed in PFA. Staining was performed as described below.

To analyze DNA damage responses of CD34-positive cells in Cul3 $3^{\text {loxP/loxP }}$ AlfpCre mice, we injected mice with doxorubicin $(0.01 \mu \mathrm{g} / \mathrm{g}$ mouse). After 48 hours, livers were harvested and fixed in PFA. Stainings were done as described below. Goldner staining was used to identify stromal cells.

Statistics. All statistical analyses were done using Prism software (GraphPad) (2-tailed $t$ test). All graphs were created using Microsoft Excel software, and error bars were calculated with Excel. All data are represented as mean \pm SD.

Western blot analysis. Tissue or liver lysates were generated as described previously (39). The protein concentration of all lysates was determined using the Bradford method (Bio-Rad) according to the manufacturer's instructions. Samples were aliquoted, shock frozen in liquid nitrogen, and stored at $-80^{\circ} \mathrm{C}$. A test gel probed for actin was run to ensure correct quantification of protein concentrations. If necessary, protein concentrations were readjusted and determined again by the Bradford method and controlled by Western blotting using an actin-specific antibody. These aliquoted lysates were used for further analyses with specific antibodies. To ensure equal transfer of proteins, gels were stained with Coomassie blue after blotting and membranes were analyzed with ink or Ponceau staining after exposure to the film.

Antibodies used for Western blotting were cyclin E (Delta Biolabs), actin (ICN), p21 (Santa Cruz Biotechnology Inc.), p16 (Biozol), ICAM1 (Abcam), Aurora B (Abcam), pChk1, p15 (Cell Signaling Technology), Cul3 (Santa Cruz Biotechnology Inc.), PKM2 (US Biological), CK14 (Progen), CD34 (BioLegend), and CD133 (Abcam, 19898). Secondary antibodies were purchased from Amersham.

Immunofluorescence staining/tissue array. Immunofluorescence staining of paraffin sections was performed using the following antibodies: CK14 (Progen), CD34 (BioLegend), CD133 (Abcam, 19898), albumin (Acris), $\gamma$-H2AX (Upstate, clone JBW301), and p16 (Biozol, LS-C32847).

Stainings of paraffin sections were done as described below.

CK14 staining: Antigen unmasking was performed in Tris/EDTA buffer, $\mathrm{pH} 9.0$, for 20 minutes. Slides were allowed to cool down slowly at room temperature. Sections were permeabilized in $0.3 \%$ Triton for 2 minutes and washed in PBS. Primary antibody was diluted 1:150 and incubated overnight at $4^{\circ} \mathrm{C}$. Slides were washed in PBS, and secondary antibody was incubated for 1 hour at room temperature at a dilution of 1:400.

CD34 staining: Antigen unmasking was performed in Tris/EDTA buffer, pH 9.0, for 20 minutes. Slides were allowed to cool down slowly at room temperature. Sections were permeabilized in $0.3 \%$ Triton for 2 minutes, washed in PBS, and incubated with primary antibody (1:50) overnight at $4^{\circ} \mathrm{C}$. Slides were washed, and secondary antibody was used at a 1:100 dilution for 1 hour at room temperature.
CD133 staining: Antigen unmasking was performed in citrate buffer, pH 6.0, for 20 minutes. Slides were allowed to cool down slowly at room temperature. Antibody was incubated overnight at a dilution of 1:50. After washing in PBS, secondary antibody was incubated at a 1:100 dilution for 1 hour at room temperature.

Cul3 staining: Antigen unmasking was performed in Tris/EDTA buffer, pH 9.0, for 20 minutes. Slides were allowed to cool down slowly at room temperature. Sections were permeabilized in $0.3 \%$ Triton for 2 minutes and washed in PBS. Endogenous peroxidase was blocked in $0.3 \% \mathrm{H}_{2} \mathrm{O}_{2}$ for 20 minutes. All other steps were done following the instructions of the TSA Kit (PerkinElmer). In short, unspecific binding was blocked using the TNB Buffer as described in the kit. Cul3 antibody (Santa Cruz Biotechnology Inc., $\mathrm{H} 293$ ) was diluted 1:100 and incubated overnight at $4^{\circ} \mathrm{C}$. Secondary antibody (anti-rabbi-biotin [Dianova]) was incubated for 1 hour at room temperature after the slides were properly washed in PBS. After washing, Streptavidin-Peroxidase was used as supplied with the TSA kit (Perkin Elmer) and incubated for 1 hour. Fluorescence substrate was incubated for 5 minutes, and after washing slides were counterstained with DAPI and mounted.

$\gamma$-H2AX, p16 costaining: Antigen retrieval was performed in $10 \mathrm{mM}$ citrate buffer (for $\gamma$-H2AX costainings) or in Tris/EDTA buffer, pH 9.0 (p16 costainings). Unspecific binding was minimized by incubation of sections with $1 \%$ BSA or by using MOM blocking reagent (Vector). Quantitation of cells was done on 3 different sections of at least 3 mice. Stem cell markers were analyzed as described above.

BrdU staining: For BrdU staining, slides were deparaffinized and antigen unmasking was performed in Tris/EDTA buffer. Double staining was performed using the Amersham Proliferation kit and CD34 and CK14 antibodies.

For immunofluorescence detection of DNA damage of cells grown on coverslips, the Abcam antibody ab11174 was used. Cells were fixed in 4\% PFA at the indicated time points for 3 minutes, washed in PBS, and permeabilized in $0.1 \%$ Triton for 5 minutes. Antibody incubation was done after blocking in 1\% BSA/PBS for 1 hour. To analyze proliferation, the Cell Proliferation Kit (Amersham) was used according to the manufacturer's instructions. Secondary antibodies for immunofluorescence were purchased from Dianova. For quantitation of DNA damage and BrdU uptake, 3 independent experiments were analyzed. All statistical analyses were done using the $t$ test and Prism 5 statistics software.

Tissue microarray analysis of human normal tissue and HCC as well as statistical analysis have been described previously (40). The following scoring system was used to represent quantity: 0 , no expression; 1 , positivity in less than $1 \%$ of tumor cells; 2 , positivity in $1 \%-9 \%$ of tumor cells; 3 , positivity in $10 \%-50 \%$ of tumor cells; 4 , positivity in more than $50 \%$ of tumor cells. Antibodies used for Cul3 staining and cyclin E were purchased from Acris (HE12) and Delta Biolabs (C19).

$\mathrm{LacZ}$ staining. Cryosections were fixed in fixing solution ( $0.2 \%$ glutaraldehyde, 50 mM EGTA, pH 7.3, $100 \mathrm{mM} \mathrm{MgCl}_{2}$ in PBS). Staining was performed overnight in staining buffer $(0.5 \mathrm{mg} / \mathrm{ml} \mathrm{X}$-gal, $5 \mathrm{mM}$ potassium ferrocyanide, $5 \mathrm{mM}$ potassium ferricyanide in $2 \mathrm{mM} \mathrm{MgCl}_{2}, 0.01 \%$ sodium deoxycholate, $0.02 \%$ Nonidet P40 in PBS; pH 7.3). The next day, section were washed in PBS, counterstained with hemalaun, and covered in Kaiser's glycerogelatin. All pictures were taken with a DM5000B microscope (Leica) using the DFC300FX camera and Leica software.

Isolation of hepatic progenitor cells. Cells were isolated by chopping fresh mouse liver tissue in media containing 10\% FCS. Supernatant and small liver pieces were transferred to a $10-\mathrm{cm}$ culture dish and cultivated overnight. The next day, half of the medium $(5 \mathrm{ml})$ was replaced with fresh medium. Cells were cultivated for 2-3 months, with half of the medium replaced every 3-4 days, until the plate was confluent. Cell lines were subjected to single clone expansion for RT-PCR and differentiation into hepatocytes. 
Differentiation of hepatic progenitor cells. Differentiation medium was prepared as described previously (28). The medium was further supplemented with $2 \%$ FCS and $40 \mathrm{ng} / \mathrm{ml} \mathrm{HGF}$ (Sigma-Aldrich) and $20 \mathrm{ng} / \mathrm{ml} \mathrm{EGF} \mathrm{(Sigma-Aldrich).}$ For differentiation experiments, cells were seeded in 12-well plates coated with collagen $\left(1 \mathrm{mg} / \mathrm{ml}\right.$; Roche) at a density of $3.2 \times 10^{4}$ cells/well. For analysis of cells by FACS sorting, CD34 staining was performed on living cells. Anti-rat Cy3 secondary antibody was used. Purity of sorted cells was $90 \%$.

Differentiation of HepG2 and HUH7 cells was achieved by plating cells on collagen-coated plates. HGF, EGF, and dexamethasone were added to the medium.

siRNA knockdown of cyclin E1 and E2, FBW7, Cul1, and Cul3. The following siRNA molecules were purchased from Ambion: ccne1 ID 161045; ccne2 ID 600056; Cul1: ID 70723; Cul3: ID 16050. Fbw7 knock down was achieved by using 3 different siRNAs targeting Fbw 7 .

siRNA was transfected at a final concentration of $10 \mathrm{nM}$. Transfections were done according to the instructions for use (HiPerFect, QIAGEN). For identification of transfected cells, a labeled control siRNA was transfected simultaneously. Transfection efficiency was approximately $90 \%$. The knockdown was confirmed by RT-PCR using Fbw7 and Cul1 primers (see below for sequences).

For determination of cyclin $\mathrm{E}$ half-lives, transfection was done in asynchronously proliferating cells 24 hours after seeding. Cycloheximide was added (final concentration, $10 \mathrm{mg} / \mathrm{ml}$ ) 72 hours after seeding the cells. Samples were taken at the time points indicated. Western blot analysis was done for cyclin E, and protein bands were quantified using Bio-Rad Quantification software (Quantity One).

HepG2 and HUH7 cells were transfected after seeding on a 6 -cm plate using $20 \mathrm{nM}$ Cul3 siRNA. After 48 hours, cells were labeled with BrdU for 12 hours and then trypsinized for FACS analysis.

FACS analysis. HUH7 and HepG2 cells were transfected with siRNA and harvested after 60 hours. Cells were resuspended in 1\% BSA, 1 mM EDTA in PBS, and $\mathrm{Cd} 133$ was stained using BD antibody 130-080-801. Cells were washed twice at $4^{\circ} \mathrm{C}$ and fixed using the BD Cytofix/Cytoperm Solution provided with the BrdU FITC Kit (51-2354AK). Analysis was done using FACSCalibur.

Transfection of progenitor cells. Cells were seeded at a density of $4 \times 10^{4}$ cells per well, which contained gelatin-coated coverslips. The next day, cells were transfected with Attractene from QIAGEN following the instructions for use. Twenty-four hours later, coverslips were fixed in PFA for 3 minutes and stained using myc-tag-specific antibody (Upstate).

$\mathrm{Cul3}$ reconstitution. Cul3-knockout clones were transfected with linearized pCS2 Cul3 plasmid and the selection plasmid pBabe Puro using Polyfect transfection reagent according to the manufacturer's protocol (Qiagen). Cells were selected with $2 \mu \mathrm{g} / \mathrm{ml}$ puromycin, and clones were selected for further analysis by Western blotting for Cul3.

Treatment with $\mathrm{H}_{2} \mathrm{O}_{2}$. Cells were seeded at a density of $4 \times 10^{4}$ cells per well on gelatin-coated coverslips. $\mathrm{H}_{2} \mathrm{O}_{2}$ was added at a concentration of $350 \mu \mathrm{M}$. Cells were harvested 30 minutes after addition of $\mathrm{H}_{2} \mathrm{O}_{2}$ and analyzed by Western blotting.

cDNA synthesis and PCR. RNA extractions were done as previously described (37). Primers used to monitor differentiation of progenitor cells into hepatocytes were: HNF1 $\alpha$ (29) dioxygenase, GST, CD34, Thy1 (41), albumin and AFP (42), PXR (43), and c-kit (44). Primers used to amplify C/EBP $\alpha$ and HNF $4 \alpha$ were as follows: C/EBP $\alpha$ forward 5'-AAAGC-
CAAGAAGTCGGTGGA-3' and C/EBP $\alpha$ reverse, $5^{\prime}$-CAGTTCACGGCTCAGCTGTT- $3^{\prime}$. HNF $4 \alpha$ forward, $5^{\prime}$-CTTCCTTCTTCATGCCAG- $3^{\prime}$ and HNF $4 \alpha$ reverse, $5^{\prime}$-ACACGTCCCCATCTGAAG-3'. Primers used to analyze expression of $\mathrm{p} 15$ and $\mathrm{p} 16$ were as follows: $\mathrm{p} 16$ forward, $5^{\prime}$-CCGCTGCAGACAGACTGGC-3'; p16 reverse, 5'-TGAGGCCGGATTTAGCTCTG-3'; p15 forward, 5'-AGATCCCAACGCCCT-3'; p15 reverse, 5'-AGATCCCAACGCCCT- $3^{\prime}$. Primers for p21 were published previously (45).

Primers used for expression analysis of Fbw7 and Cul3 (wild-type and deleted version) were as follows: Fbw7 forward, 5'-CAAATCTCCTAAGGTGCTGAAAGGGCATG-3' and reverse, 5' -CCACATGGATGCCATCAAACTGTAATGAATAG-3'; Cul3 forward, 5'-ATAAATAAGGTGCGAGAAGAT-3' and reverse, $5^{\prime}$-AgTCAAAGGgCTAACAGAAC-3'. For Cul3, PCR products were gel purified and sequenced by Agowa to confirm deletion of the Cul3 fragment.

Primers used to amplify human Cul3 were 5 '-ATGACCATGGAT-

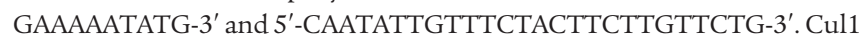
primers to analyze knockdown upon siRNA treatment were Cul1 forward, 5'-CAAATCTTCTTAAGGATGGAGAAGATTTAATG-3' and Cul1 reverse, 5'-CAGCCCCAATTCCACATAAGATTG-3'.

$P A S$ staining and $\beta$-galactosidase staining. Cells grown on coverslips were fixed in 4\% PFA for 3 minutes, washed in PBS, and subjected to permeabilization in $0.1 \%$ Triton for 10 minutes. Cells were then washed in distilled water and treated with $1 \%$ periodic acid for 5 minutes. Cells were extensively washed with distilled water and incubated in Schiff reagent for 10 minutes. After cells were washed with tap water, they were mounted in gelatin. To confirm specific staining of glycogen after permeabilization, we treated cells with $5 \mathrm{mg} / \mathrm{ml}$ diastase for 30 minutes at $37^{\circ} \mathrm{C}$.

Senescence-associated $\beta$-galactosidase activity was analyzed by incubating cells in freshly prepared staining solution $(1 \mathrm{mg} / \mathrm{ml} 5$-bromo- 4 chloro3-indolyl $\beta$-D galactosidase in DMF/40 mM citric acid ( $\mathrm{pH} 5.8$ ), $5 \mathrm{mM}$ potassium ferrocyanide, $5 \mathrm{mM}$ potassium ferricyanide, $150 \mathrm{mM} \mathrm{NaCl}$, and $2 \mathrm{mM} \mathrm{MgCl}_{2}$ ). Cells were incubated at $37^{\circ} \mathrm{C}$ for 24 hours.

Array comparative genomic bybridization. Array comparative genomic hybridization was performed using Agilent Mouse Genome Microarray Kit 244A (Agilent Technologies), a high-resolution 60-mer oligonucleotidebased microarray with median probe spacing of about $6.4 \mathrm{~kb}$. Labeling and hybridization of genomic DNA were performed according to the protocol provided by Agilent.

\section{Acknowledgments}

We thank Sarah Messnard for expert technical assistance. We also thank Holly Sundberg Malek, Arnaud Besson, James M. Roberts, Lars Zender, and Lenhard Rudolph for critical advice. This work was supported by grants from Deutsche Krebshilfe (Max Eder Program) and Deutsche Forschungsgemeinschaft to N.P. Malek.

Received for publication December 7, 2009, and accepted in revised form July 21, 2010.

Address correspondence to: Nisar P. Malek, Hannover Medical School, Carl Neuberg Strasse 1, 30625 Hannover, Germany. Phone: 01149.511.532.4585; Fax: 01149.511.532.428; E-mail: Malek.Nisar@MH-Hannover.de.

\footnotetext{
1. Malumbres M, Barbacid M. To cycle or not to cycle: a critical decision in cancer. Nat Rev Cancer. 2001; 1(3):222-231.

2. Masaki T, et al. Cyclins and cyclin-dependent kinases: comparative study of hepatocellular carcinoma versus cirrhosis. Hepatology. 2003;37(3):534-543.

3. Spruck CH, Won KA, Reed SI. Deregulated cyclin $\mathrm{E}$ induces chromosome instability. Nature.
}

1999;401(6750):297-300.

4. Welcker M, Clurman BE. FBW7 ubiquitin ligase: a tumour suppressor at the crossroads of cell division, growth and differentiation. Nat Rev Cancer. 2008;8(2):83-93

5. Strohmaier H, Spruck CH, Kaiser P, Won KA, Sangfelt O, Reed SI. Human F-box protein hCdc4 targets cyclin $\mathrm{E}$ for proteolysis and is mutated in a breast cancer cell line. Nature. 2001;413(6853):316-322.

6. Akhoondi S, et al. FBXW7/hCDC4 is a general tumor suppressor in human cancer. Cancer Res. 2007;67(19):9006-9012.

7. Onoyama I, et al. Conditional inactivation of Fbxw7 impairs cell-cycle exit during T cell differentiation and results in lymphomatogenesis. J Exp Med. 2007;204(12):2875-2888. 
8. Matsuoka S, et al. Fbxw7 acts as a critical fail-safe against premature loss of hematopoietic stem cells and development of T-ALL. Genes Dev. 2008; 22(8):986-991.

9. Thompson BJ, et al. Control of hematopoietic stem cell quiescence by the E3 ubiquitin ligase Fbw7. J Exp Med. 2008;205(6):1395-1408.

10. Minella AC, et al. Cyclin E phosphorylation regulates cell proliferation in hematopoietic and epithelial lineages in vivo. Genes Dev. 2008;22(12):1677-1689.

11. Singer JD, Gurian-West M, Clurman B, Roberts JM. Cullin-3 targets cyclin $\mathrm{E}$ for ubiquitination and controls S phase in mammalian cells. Genes Dev. 1999;13(18):2375-2387.

12. Pintard L, et al. The BTB protein MEL-26 is a substrate-specific adaptor of the CUL-3 ubiquitinligase. Nature. 2003;425(6955):311-316.

13. Zhang Q, Zhang L, Wang B, Ou CY, Chien CT, Jiang J. A hedgehog-induced BTB protein modulates hedgehog signaling by degrading Ci/Gli transcription factor. Dev Cell. 2006;10(6):719-729.

14. Zhang DD, Lo SC, Cross JV, Templeton DJ, Hannink M. Keap 1 is a redox-regulated substrate adaptor protein for a Cul3-dependent ubiquitin ligase complex. Mol Cell Biol. 2004;24(24):10941-10953.

15. Angers S, et al. The KLHL12-Cullin-3 ubiquitin ligase negatively regulates the Wnt-beta-catenin pathway by targeting Dishevelled for degradation. Nat Cell Biol. 2006;8(4):348-357.

16. McEvoy JD, Kossatz U, Malek N, Singer JD. Constitutive turnover of cyclin E by Cul3 maintains quiescence. Mol Cell Biol. 2007;27(10):3651-3666.

17. Kellendonk C, Opherk C, Anlag K, Schutz G, Tronche F. Hepatocyte-specific expression of Cre recombinase. Genesis. 2000;26(2):151-153.

18. Mishra L, et al. Liver stem cells and hepatocellular carcinoma. Hepatology. 2009;49(1):318-329.

19. Lemaigre F, Zaret KS. Liver development update: new embryo models, cell lineage control, and morphogenesis. Curr Opin Genet Dev. 2004;14(5):582-590.

20. Libbrecht L, Roskams T. Hepatic progenitor cells in human liver diseases. Semin Cell Dev Biol. 2002;13(6):389-396.

21. Duncan AW, Dorrell C, Grompe M. Stem cells and liver regeneration. Gastroenterology. 2009;
137(2):466-481.

22. Sumara I, et al. A Cul3-based E3 ligase removes Aurora B from mitotic chromosomes, regulating mitotic progression and completion of cytokinesis in human cells. Dev Cell. 2007;12(6):887-900.

23. Bartkova J, et al. Oncogene-induced senescence is part of the tumorigenesis barrier imposed by DNA damage checkpoints. Nature. 2006;444(7119):633-637.

24. Loeb KR, et al. A mouse model for cyclin E-dependent genetic instability and tumorigenesis. Cancer Cell. 2005;8(1):35-47.

25. Loonstra A, et al. Growth inhibition and DNA damage induced by Cre recombinase in mammalian cells. Proc Natl Acad Sci U S A. 2001;98(16):9209-9214.

26. Collado M, Blasco MA, Serrano M. Cellular senescence in cancer and aging. Cell. 2007;130(2):223-233.

27. Halazonetis TD, Gorgoulis VG, Bartek J. An oncogene-induced DNA damage model for cancer development. Science. 2008;319(5868):1352-1355.

28. Block GD, et al. Population expansion, clonal growth, and specific differentiation patterns in primary cultures of hepatocytes induced by HGF/SF, EGF and TGF alpha in a chemically defined (HGM) medium. J Cell Biol. 1996;132(6):1133-1149.

29. Li J, Ning G, Duncan SA. Mammalian hepatocyte differentiation requires the transcription factor HNF-4alpha. Genes Dev. 2000;14(4):464-474.

30. Costa RH, Kalinichenko VV, Holterman AX, Wang $X$. Transcription factors in liver development, differentiation, and regeneration. Hepatology. 2003; 38(6):1331-1347.

31. Ishii $\mathrm{K}$, et al. Hepatic differentiation of human bone marrow-derived mesenchymal stem cells by tetracycline-regulated hepatocyte nuclear factor 3beta. Hepatology. 2008;48(2):597-606.

32. Ozturk M. Genetic aspects of hepatocellular carcinogenesis. Semin Liver Dis. 1999;19(3):235-242.

33. Marino S, Vooijs M, van Der Gulden H, Jonkers J, Berns A. Induction of medulloblastomas in p53null mutant mice by somatic inactivation of $\mathrm{Rb}$ in the external granular layer cells of the cerebellum. Genes Dev. 2000;14(8):994-1004.

34. Wilkens L, et al. Induction of aneuploidy by increasing chromosomal instability during dedifferentiation of hepatocellular carcinoma. Proc Natl Acad Sci
US A. 2004;101(5):1309-1314.

35. Ou CY, Lin YF, Chen YJ, Chien CT. Distinct protein degradation mechanisms mediated by Cul1 and Cul 3 controlling Ci stability in Drosophila eye development. Genes Dev. 2002;16(18):2403-2414.

36. Roskams TA, Libbrecht L, Desmet VJ. Progenitor cells in diseased human liver. Semin Liver Dis. 2003;23(4):385-396.

37. Kossatz U, Dietrich N, Zender L, Buer J, Manns MP, Malek NP. Skp2-dependent degradation of $\mathrm{p} 27 \mathrm{kip} 1$ is essential for cell cycle progression. Genes Dev. 2004;18(21):2602-2607.

38. Nickeleit I, et al. Argyrin a reveals a critical role for the tumor suppressor protein $\mathrm{p} 27$ (kip1) in mediating antitumor activities in response to proteasome inhibition. Cancer Cell. 2008;14(1):23-35.

39. Malek NP, Sundberg H, McGrew S, Nakayama K, Kyriakides TR, Roberts JM. A mouse knock-in model exposes sequential proteolytic pathways that regulate p27Kip1 in G1 and S phase. Nature. 2001; 413(6853):323-327.

40. Singer S, et al. Protumorigenic overexpression of stathmin/Op18 by gain-of-function mutation in p53 in human hepatocarcinogenesis. Hepatology. 2007;46(3):759-768.

41. Suzuki A, et al. Clonal identification and characterization of self-renewing pluripotent stem cells in the developing liver. J Cell Biol. 2002; 156(1):173-184.

42. Ogawa $S$, et al. Crucial roles of mesodermal cell lineages in a murine embryonic stem cell-derived in vitro liver organogenesis system. Stem Cells. 2005;23(7):903-913.

43. Xu DX, et al. Perinatal lipopolysaccharide exposure downregulates pregnane X receptor and Cyp3a11 expression in fetal mouse liver. Toxicol Sci. 2005; $87(1): 38-45$.

44. Kotton DN, Fabian AJ, Mulligan RC. A novel stem-cell population in adult liver with potent hematopoietic-reconstitution activity. Blood. 2005; 106(5):1574-1580.

45. Ludtke TH, Christoffels VM, Petry M, Kispert A. Tbx3 promotes liver bud expansion during mouse development by suppression of cholangiocyte differentiation. Hepatology. 2009;49(3):969-978. 